\title{
Netrin-DCC, Robo-Slit, and Heparan Sulfate Proteoglycans Coordinate Lateral Positioning of Longitudinal Dopaminergic Diencephalospinal Axons
}

\author{
Edda Kastenhuber, ${ }^{1}$ Ursula Kern, ${ }^{1}$ Joshua L. Bonkowsky, ${ }^{3,4}$ Chi-Bin Chien, ${ }^{3}$ Wolfgang Driever, ${ }^{1,2}$ and Joern Schweitzer \\ ${ }^{1}$ Developmental Biology, Institute of Biology 1, Faculty of Biology and ${ }^{2}$ Freiburg Institute for Advanced Studies, University of Freiburg, 79104-D Freiburg, \\ Germany, ${ }^{3}$ Department of Neurobiology and Anatomy, University of Utah, Salt Lake City, Utah 84132, and ${ }^{4}$ Department of Pediatric Neurology and \\ Pediatrics, University of Utah Medical Center, Salt Lake City, Utah 84132
}

\begin{abstract}
Longitudinal axons provide connectivity between remote areas of the nervous system. Although the molecular determinants driving commissural pathway formation have been well characterized, mechanisms specifying the formation of longitudinal axon tracts in the vertebrate nervous system are largely unknown. Here, we study axon guidance mechanisms of the longitudinal dopaminergic (DA) diencephalospinal tract. This tract is established by DA neurons located in the ventral diencephalon and is thought to be involved in modulating locomotor activity. Using mutant analysis as well as gain of function and loss of function experiments, we demonstrate that longitudinal DA axons navigate by integrating long-range signaling of midline-derived cues. Repulsive Robo2/Slit signaling keeps longitudinal DA axons away from the midline. In the absence of repulsive Robo2/Slit function, DA axons are attracted toward the midline by DCC (deleted in colorectal cancer)/Netrin1 signaling. Thus, Slit-based repulsion counteracts Netrin-mediated attraction to specify lateral positions of the DA diencephalospinal tract. We further identified heparan sulfate proteglycans as essential modulators of DA diencephalospinal guidance mechanisms. Our findings provide insight into the complexity of positioning far-projecting longitudinal axons and allow us to provide a model for DA diencephalospinal pathfinding. Simultaneous integrations of repulsive and attractive long-range cues from the midline act in a concerted manner to define lateral positions of DA longitudinal axon tracts.
\end{abstract}

\section{Introduction}

During embryonic development, longitudinal tracts set up by pioneer axons are among the first axon pathways to be established (Chitnis and Kuwada, 1990; Wilson et al., 1990; Easter et al., 1993, 1994; Chedotal et al., 1995; Mastick and Easter, 1996). Although longitudinal tracts are of great importance, since they convey information between the brain and spinal cord, little is known about the factors guiding their axonal outgrowth. Longitudinal axons project parallel to the midline of the nervous system, which contains the floor plate, a source of guidance cues (Colamarino and Tessier-Lavigne, 1995; Charron and TessierLavigne, 2005). Here, growth cones of spinal commissural neurons, to appropriately cross the midline, have to interpret combinations of short-range and long-range attractive or repulsive cues (Serafini et al., 1996; Zou et al., 2000; Charron et al.,

\footnotetext{
Received Feb. 3, 2009; accepted May 14, 2009.

This work was supported by grants to W.D. [Deutsche Forschungsgemeinschaft (DFG)-SFB505-B7, DFG-SFB780B6, and European Union-ZF-MODELS] and J.S. (DFG-SCHW1404/1-1). We thank R. Ramchandran for robo4 CDNA, Hitoshi Okamoto for the generous gift of the Tg(hsp70l:slit2-GFP) ${ }^{r w 015 a}$ transgenic zebrafish, and Harold Burgess and Michael Granato for the twt ${ }^{t w 204}$ mutants. The box ${ }^{t m 70 g}$ mutants were obtained from the Tübingen zebrafish stock center. We also thank the zebrafish community for sharing other reagents, Katrin Hübscher for excellent technical assistance, and S. Götter for expert zebrafish care.

Correspondence should be addressed to either Dr. Joern Schweitzer or Dr. Wolfgang Driever, Institute of Biology 1, University of Freiburg, Hauptstrasse 1, D-79104 Freiburg, Germany, E-mail: joern.schweitzer@biologie.unifreiburg.de or driever@biologie.uni-freiburg.de.

DOI:10.1523/JNEUROSCI.0568-09.2009

Copyright $\odot 2009$ Society for Neuroscience $\quad$ 0270-6474/09/298914-13\$15.00/0
}

2003; Long et al., 2004; Sabatier et al., 2004). Longitudinal axons grow through the same environment such as commissural axons and thus may use the same molecular signals. Two candidates for controlling longitudinal axon guidance are Slits and Netrins. Both are secreted axonal guidance cues expressed by the ventral midline along the anterior-posterior axis (Kennedy et al., 1994; Harris et al., 1996; Brose et al., 1999). Slits and Netrins bind to their receptors of the Robo and Frazzled/DCC families, respectively, and are involved in various aspects of axonal patterning (Chedotal, 2007; Moore et al., 2007). Genetic studies in Drosophila have demonstrated that differential expression of Robo receptors in combination with Slit signaling from the midline defines the lateral position of post-crossing commissural or longitudinal axons (Rajagopalan et al., 2000; Simpson et al., 2000), a process that may also require Frazzled-DCC/Netrin function (Bhat, 2005; Garbe and Bashaw, 2007). Studies in vertebrates hint to an analogous Robo code for lateral positioning of post-crossing commissural axons (Long et al., 2004) or longitudinal axons (Farmer et al., 2008). Whether DCC/Netrin function is additionally required in this process is currently not known.

Netrins, Slits, and their receptors bind to heparan sulfate proteoglycans (HSPGs) or heparan sulfates (HSs) (Serafini et al., 1994; Bennett et al., 1997; Liang et al., 1999; Johnson et al., 2004). Furthermore, genetic studies in various model organisms have provided evidence that HSs or HSPGs are modulators of Robo/ Slit (Inatani et al., 2003; Johnson et al., 2004; Lee et al., 2004) or DCC/Netrin (Matsumoto et al., 2007) signaling at the midline. 
Here, we have investigated mechanisms controlling diencephalospinal longitudinal tract formation of dopaminergic (DA) neurons located in the posterior tuberculum of zebrafish. These neurons have been shown to be homologous to the mammalian diencephalic A11 DA group neurons (Ryu et al., 2007), which are involved in spinal motor control and may be affected in restless legs syndrome (RLS), a widespread neurological disorder (Clemens et al., 2006; Ondo et al., 2007). We show that lateral positioning of longitudinal DA axons in astray/robo 2 mutants is defective. Instead of choosing a lateral route parallel to the midline, THir axons grow toward and eventually cross the midline. We further demonstrate that ubiquitous misexpression of Slit2 impairs longitudinal pathfinding of DA axons leading to aberrant midline crossing. Knocking down either $d c c$ or netrin 1 function in astray mutants leads to a partial rescue of the observed pathfinding errors. Together, these data show that repulsion by Robo2/Slit and simultaneous attraction by DCC/Netrin 1 act in opposition to specify lateral positions of longitudinal DA axons in the hindbrain. Finally, we demonstrate a requirement of HS or HSPG function for lateral positioning of longitudinal DA axons.

\section{Materials and Methods}

Fish maintenance. Zebrafish maintenance and breeding were carried out under standard conditions at $28.5^{\circ} \mathrm{C}$ (Westerfield, 1995). Embryos were staged and fixed at desired time points [hours postfertilization (hpf)] in $4 \%$ paraformaldehyde in PBS. To avoid formation of melanin pigments, we incubated embryos in $0.2 \mathrm{~mm}$ 1-phenyl-2 thiourea (Sigma).

Fish lines. The following alleles were used: astray (ast $t^{t i 272 z}$ and ast ${ }^{\text {te284 }}$ ) (Fricke et al., 2001), boxer (box ${ }^{\text {tm70g }}$ ) (Lee et al., 2004), twitch twice (twt ${ }^{\text {tw204}}$ ) (Granato et al., 1996; Burgess et al., 2009), and $\mathrm{Tg}$ (hsp70l:slit2GFP) ${ }^{r w 015 a}$ (Yeo et al., 2001). ast homozygotes are adult viable and fertile. For most experiments, homozygous ast fish were mated with one another to produce eggs for morpholino injections. ast/+ embryos were generated by crossing ast homozygous fish with $\mathrm{AB} / \mathrm{TL}$ wild-type fish. Homozygous ast $t^{t i 272 z}$ embryos were identified by PCR using the primers ASA4R (5' -CAGCTCCTTTTGCACATGTTT-3'), ASA5R (5' -CAGCTCCTTTTGCACATGTTA- ${ }^{\prime}$ ), and CF9F (5'-GAATGACTCCTCGTCGCTCT-3'). The primers were designed in such a way that ASA4R and CF9F specifically amplify the wild-type (WT) allele, whereas ASA5R and CF9F specifically amplify the mutant $a s t^{t i 272 z}$ allele. Primers were annealed at $55^{\circ} \mathrm{C}$, and the amplified product size was $185 \mathrm{bp}$. Homozygous ast ${ }^{\text {te284 }}$ embryos were identified as described by Chalasani et al. (2007). Homozygous box ${ }^{t m 70 g}$ embryos have completely penetrant pectoral fin and jaw phenotypes and lack swim bladders, allowing us to identify mutants after 72 hpf. To identify heterozygous box mutants, embryos were genotyped as described by Lee et al. (2004). twt ${ }^{\text {tw204 }}$ embryos were genotyped as described previously (Burgess et al., 2009). ast ${ }^{t i 272 z} / t w t^{t w 204}$ and $a s t^{t i 272 z} / b o x^{t m 70 g}$ compound mutants were generated by incrossing identified $a s t^{t i 272 z} /+; t w t^{t w 204} /+$ or box $x^{t m 70 g} /+; a s t^{t i 272 z} /+$ adults.

Whole-mount antibody staining. TH was detected using an antizebrafish-TH antibody (1:500) (Ryu et al., 2007). zn5 [recognizing Alcam/ DM-GRASP/neurolin (Trevarrow et al., 1990)] and 3A10 [visualizing neurofilaments; (Dodd et al., 1988)] were obtained as supernatants from the Developmental Studies Hybridoma Bank) and used at 1:500 and 1:50, respectively, 10E4 (anti-human heparan sulfate; US Biological) was used at 1:50, and clone 6-11B-1 (Sigma) against acetylated $(\alpha)$-tubulin was used at 1:1000. Secondary antibodies used were either coupled to Alexa 555, Alexa 488, or Alexa 647 (Invitrogen) or HRP (Dianova). Whole-mount immunohistochemistry was performed as described previously (Holzschuh et al., 2003). For double labeling, embryos were simultaneously incubated with both primary and subsequently both secondary antibodies. After immunohistochemistry, embryos were cleared in a graded glycerol series and mounted in $100 \%$ glycerol.

Whole-mount in situ hybridization. Whole-mount in situ hybridization (WHISH) using alkaline phosphatase-based color reaction was performed as described previously (Hauptmann and Gerster, 1994). Digoxigenin-labeled probes were prepared with RNA-labeling reagents
(Roche). The following antisense probes were used: th (Holzschuh et al., 2001), robo1, robo2, and robo3 (Lee et al., 2001), robo4 (Bedell et al., 2005), dcc (Fricke and Chien, 2005), slit1a and slit1b (Hutson et al., 2003), slit2 and slit3 (Yeo et al., 2001), netrin1a (Lauderdale et al., 1997), netrin1b (Strahle et al., 1997), and shh (Krauss et al., 1993). Single or double fluorescent in situ hybridization (FISH) was carried out as described previously (Filippi et al., 2007). To combine FISH with TH immunohistochemistry, FISH was first performed followed by $\mathrm{TH}$ immunohistochemistry.

Morpholino oligonucleotide sequences and injections. The following morpholino oligonucleotides (MOs) were obtained from Gene Tools. Control MO was a standard control from Gene Tools: (5' -CCTCTTACCTCAGTTACAATTTATA-3'); $d c c$-MO1 (5'-GAATATCTCCAGTGACGCAGCCCAT-3'); dcc-MO2 (5-GCGAAATC-CGCTGCTAATCAATCAA-3'); netrin1a (5'-ATGATGGACTTACCGACACATTCGT$\left.3^{\prime}\right)$; netrin $1 b$ (5' -CGCACGTTACCAAAATCCTTATCAT-3'); slit1a $\left(5^{\prime}\right.$ GAAATAAACTCACAGCCTCTCGGTG-3'); slit1b (5'-GCTCGGTGTCCGGCATCTCCAAAAG-3'); slit2 (5'-CATCACCGCTGTTTCCTCAAGTTCT- $\left.3^{\prime}\right)$; slit3 $\left(5^{\prime}\right.$-TATATCCTCTGAGGCTGATAGCAGC- $\left.3^{\prime}\right)$; tfap $2 \alpha \quad\left(5^{\prime}\right.$-CCTCCATTCTTAGATTTGGCCCTAT-3'); and robo 1 ( $5^{\prime}$-CGCGTTTTAGATAGATGCTTGTGTA- ${ }^{\prime}$ ).

All MOs were previously described and shown to functionally knock down dcc or netrin1 (Suli et al., 2006), slit1a (Campbell et al., 2007), slit1b (Zolessi et al., 2006), slit2, slit3 (Barresi et al., 2005), tfap2 $\alpha$ (Hoffman et al., 2007), and robol (Devine and Key, 2008) gene functions. MOs were diluted to desired concentrations in water and phenol red $(0.5 \%$ final concentration) and pressure injected into one-cell stage embryos. The injected volume was calculated using a calibrated eyepiece micrometer. For proper controls, we always injected embryos from the same clutch with control and specific MOs.

Microscopy and image analysis. Light images were acquired using a Zeiss Axioskop compound microscope equipped with a ProgRes 3008 digital camera. Confocal z-stacks were recorded using Zeiss LSM 510 or a Zeiss LSM 5 DUO laser scanning confocal microscope. LSM or NIH ImageJ software were used to create z-projections, and Adobe Photoshop and Adobe Illustrator were used to merge images and compose figures.

\section{Results}

Lateral positioning of longitudinal DA axon tracts requires Robo2 To study axon guidance mechanisms of descending longitudinal DA projections, we at first described their formation using $\mathrm{TH}$ immunohistochemistry in detail. $\mathrm{TH}$ is the rate-limiting enzyme in catecholamine biosynthesis and is expressed by DA and noradrenergic (NA) neurons (Holzschuh et al., 2001). Confocal z-projections of $24 \mathrm{hpf}$ embryos labeled with $\mathrm{TH}$ antibody revealed that DA neurons located in the ventral diencephalon send out their axons on a longitudinal path toward the spinal cord. These axons project ipsilaterally and grow at a defined distance toward the midline (Fig. 1A). Double labeling using anti-TH and antiacetylated tubulin antibodies revealed that these early DA axons do not grow within the medial longitudinal fascicle (MLF) but grow in close vicinity to MLF axons (supplemental Fig. $S 1 A-C$, available at www.jneurosci.org as supplemental material). z-projections of confocal image stacks of embryos at 36,48 , and $72 \mathrm{hpf}$ indicated that additional THir fibers derived from later differentiating DA neurons fasciculate with the early DA axons to generate a discrete longitudinal fascicle on each side of the embryo (Fig. $1 C, E, G$ ). These fascicles do not cross the midline and always select a specific position lateral to the midline, which is approximately at the level of the NA locus ceruleus (LC) neurons (Figs. 1C, 2A).

Because studies in Drosophila and vertebrates have demonstrated that Robo/Slit signaling specifies lateral positioning of longitudinal axon tracts (Rajagopalan et al., 2000; Simpson et al., 2000; Garbe and Bashaw, 2007; Farmer et al., 2008), we decided to inspect pathfinding of longitudinal THir axons in Robo2deficient astray mutants. We used two different astray alleles, 
ast ${ }^{t i 272 z}$ mutants (ast) lacking functional Robo 2 receptor and $a s t^{\text {te284 }}$ mutants with remaining low levels of residual Robo2 function (Fricke et al., 2001; Chalasani et al., 2007). Confocal analysis revealed that at $24 \mathrm{hpf}$ longitudinal THir axon tract formation of the earliest diencephalic DA neurons in ast mutant embryos is indistinguishable from heterozygous siblings (Fig. $1 A, B$ ) and WT embryos (supplemental Fig. S1 $A$, available at www.jneurosci.org as supplemental material). In contrast, inspecting THir axon tract formation in the hindbrain of ast mutants between 36 and $72 \mathrm{hpf}$ revealed abnormal DA pathfinding compared with ast/+ or WT embryos. Instead of retaining their lateral positions on each side of the embryo, longitudinal DA axons in ast gradually shift toward the midline and establish more medial longitudinal paths (Fig. $1 D$, $F, H)$. This observation is not caused by a narrower hindbrain, since the distance between the LC neurons was unchanged in ast compared with ast/+ embryos (Figs. $1 C, D, 2 A, D)$. In addition to the observed medial shift of THir axons, ectopic midline crossing of THir axons was observed occasionally in ast (Fig. 1D). These phenotypes were never detected in ast/+ or WT (data not shown) embryos. Higher magnification revealed that pathfinding of THir axons in ast embryos is almost normal up to the level of the LC neurons. In this region, THir axons gradually project toward the midline (Fig. 2A-F). Misguided THir axons in ast could be followed up to the level of the spinal cord (Fig. $2 G-L)$. Inspecting THir axons in ast ${ }^{\text {te284 }}$ mutants revealed the same phenotype (supplemental Fig. S1D, E, available at www. jneurosci.org as supplemental material).

In ast mutants, normal development of DA neurons in the ventral diencephalon and of hindbrain structures was demonstrated by th in situ hybridization and labeling of the MLF, reticulospinal, and commissural axons, respectively (see supplemental text and Fig. S2, available at www.jneurosci.org as supplemental material). Preventing NA neuron differentiation using a morpholino against $t f a p 2 a$ (Holzschuh et al., 2003) indicated that THir axons in the hindbrain of WT or ast embryos are of dopaminergic origin (see supplemental text and Fig. S3, available at www.jneurosci.org as supplemental material).

Thus, whereas longitudinal DA axons in the hindbrain of WT or $a s t /+$ select a specific position lateral to the midline and are confined to this pathway during development, Robo2-deficient DA axons gradually shift toward the midline and establish more medial longitudinal paths, with occasional aberrant midline crossing. These genetic results demonstrate that repulsion mediated by Robo2 is

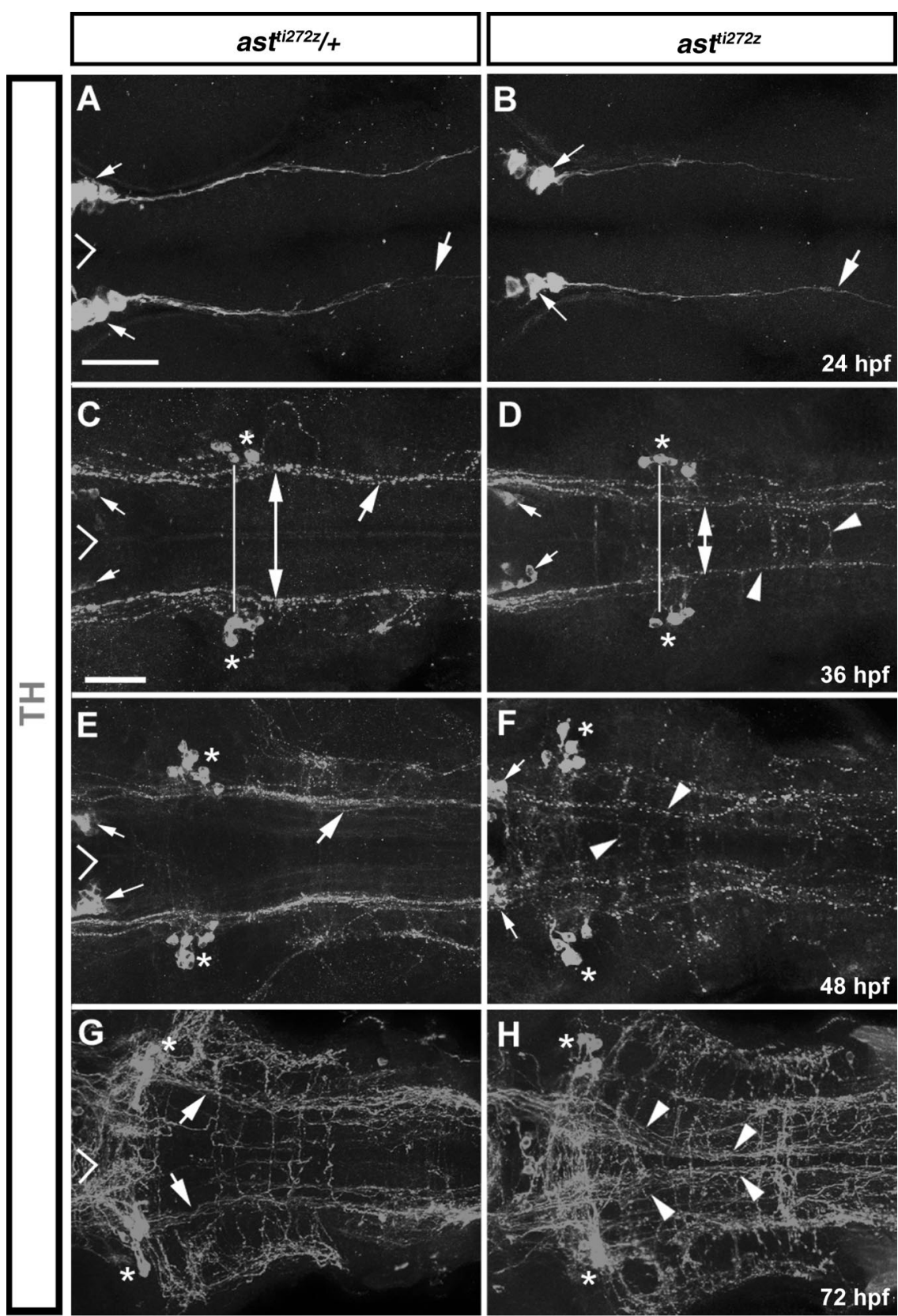

Figure 1. Lateral positioning of longitudinal $D A$ axon tracts is altered in ast mutants. $\mathbf{A}-\boldsymbol{H}$, Dorsal views of confocal z-projections of midbrain-hindbrain regions of heterozygous ast/ $+(\boldsymbol{A}, \boldsymbol{C}, \boldsymbol{E}, \boldsymbol{G})$ and homozygous ast mutant $(\boldsymbol{B}, \boldsymbol{D}, \boldsymbol{F}, \boldsymbol{H})$ embryos labeled with TH antibody are shown, anterior on left. $A, B$, Pathfinding of longitudinal TH-positive axons (large white arrows) is indistinguishable in ast/+ and ast embryos at $24 \mathrm{hpf}$. C, At $36 \mathrm{hpf}$, longitudinal TH-positive axons (arrow) in ast/+ embryos grow at a certain distance toward the midline (double arrow), whereas TH labeling of ast embryos (D) revealed axons that grow closer to or even cross the midline (arrowheads). The white lines in $\boldsymbol{B}$ and $\boldsymbol{D}$ indicate similar distance of $\mathrm{L}($ neurons. $\boldsymbol{E}, \boldsymbol{G}, \ln$ ast/+ embryos, the longitudinal TH-positive tracts are joined by more TH-positive axons to form a tight fascicle (arrows in $\boldsymbol{E}$ and $\boldsymbol{G}$ ) at 48 and $72 \mathrm{hpf}$. $\boldsymbol{F}, \boldsymbol{H}$, In ast embryos at 48 and $72 \mathrm{hpf}$, TH labeling reveals additional TH-positive axons growing toward or even crossing the midline (arrowheads in $\boldsymbol{F}$ and $\boldsymbol{H}$ ). TH-positive axons seem to linger at the midline in $72 \mathrm{hpf}$ ast embryos ( $\boldsymbol{H}$; arrowheads). Asterisks indicate noradrenergic $\mathrm{LC}$ neurons. Small arrows indicate $\mathrm{DA}$ neurons in the diencephalon. Open triangle at left side in $\boldsymbol{A}-\boldsymbol{D}$ indicates the midline. Scale bars: (in $A) A, B, 50 \mu \mathrm{m}$; (in $C) C-H, 50 \mu \mathrm{m}$.

required to specify the lateral position of DA longitudinal tracts in the hindbrain of zebrafish.

Spatial expression patterns of robo/slit and dcc/netrin genes are consistent with a role as guidance cues for longitudinal DA tracts To analyze whether Robo2 is the sole arbiter to specify lateral positions of DA longitudinal axons, we analyzed the expression of 


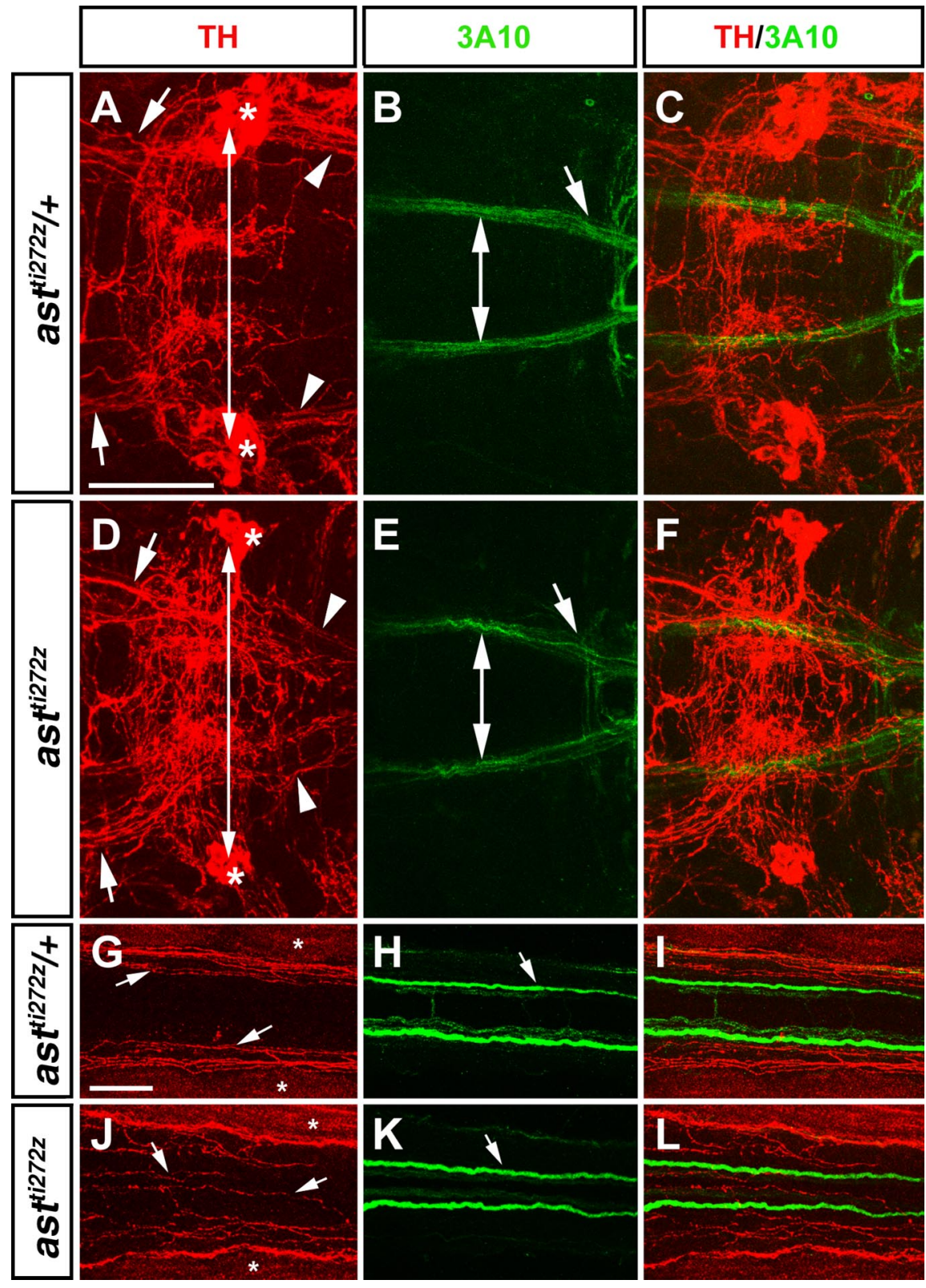

Figure 2. Robo2 function is required to establish lateral positions of THir longitudinal tracts. $A-L$, Dorsal views of confocal z-projections of the hindbrain area covering the $L C(\boldsymbol{A}-\boldsymbol{F})$ or the posterior spinal cord $(\boldsymbol{G}-\boldsymbol{L})$ labeled with TH and $3 \mathrm{~A} 10$ antibody at 72 hpf are shown, anterior on left. $\boldsymbol{A}-\boldsymbol{C}$, In ast $t^{\text {tiz272z }} /+$ embryos, THir axons derived from the ventral diencephalon ( $A$; arrows) avoid the midline and grow at a certain distance toward the midline ( $A$; arrowheads). In contrast, $3 A 10$-positive axons of the nucMLF turn toward the midline at the level of the LC (arrow in $\boldsymbol{B}$ ). Merge of both channels in $\boldsymbol{C}$ demonstrates different projection behavior of THir-positive and 3A10-positive axons. $\boldsymbol{D}-\boldsymbol{F}$, In ast ${ }^{\text {tiz72z }}$ embryos, pathfinding of THir axons is almost normal up to the level of the LC ( $\boldsymbol{D}$; arrows), but instead of selecting a lateral position, axons gradually shift toward the midline and establish more medial longitudinal paths ( $\boldsymbol{D}$; arrowheads). Turning of 3A10-positive axons toward the midline is unaffected in ast $t^{\text {tiz } 72 z}$ embryos (arrow in E). Merge of both channels in $\boldsymbol{F}$ indicate that THir-positive and 3A10-positive axons project through the similar environment at the level of the $L C$ in ast ${ }^{\text {tiz } 22 z}$. G- $L$, In the spinal cord of ast tiz72z/+ embryos THir axons (G; arrows) project lateral to the 3A10-positive Mauthner axons (arrow in $\boldsymbol{H}$, see merge in $\boldsymbol{I})$. In ast ${ }^{\text {tiz72z }}$ embryos, THir axons ( $\boldsymbol{J}$; arrows) can be detected which grow in between the Mauthner axons (arrow in $\boldsymbol{K}$, see merged channels in $\boldsymbol{L}$ ). Double arrows in $\boldsymbol{A}$ and $\boldsymbol{D}$ indicate similar distance of $\mathrm{L}(\mathrm{n}$ neurons. Asterisks in $\boldsymbol{A}$ and $\boldsymbol{D}$ indicate $\mathrm{LC}$ neurons. Asterisks in $\boldsymbol{G}$ and $\boldsymbol{J}$ point to background staining. Scale bars: (in $\boldsymbol{A}) \boldsymbol{A}-\boldsymbol{F}, 50 \mu \mathrm{m}$; in $(\boldsymbol{G})$ G-L, $50 \mu \mathrm{m}$.

other members of the Robo family in relation to DA axonal outgrowth during embryonic development. We also examined the expression of Slits, which are ligands for Robo receptors. In addition, we determined the expression of Netrin/DCC members, which in Drosophila are required to specify lateral positions of longitudinal axon tracts (Bhat, 2005; Garbe and Bashaw, 2007).
To analyze the expression of these genes in relation to DA neurons and their axonal projections, we used a combination of fluorescent WHISH and TH immunohistochemistry. At $24 \mathrm{hpf}$, shortly after the first DA neurons in the ventral diencephalon differentiate and start to send out their axons into the spinal cord (McLean and Fetcho, 2004), dcc and robo2 were expressed in broad domains that appeared to include DA neurons in the ventral diencephalon (Fig. 3A-F) Examination of confocal image planes individually demonstrated that $d c c$ and robo2 are coexpressed within the same diencephalic DA neurons (Fig. 3G-J). Coexpression of $d c c$ and robo2 in DA neurons in the ventral diencephalon was also demonstrated at 36 hpf (data not shown). Expression of robo1, robo3, and robo4 in diencephalic DA neurons during early stages of DA axonal outgrowth between 24 and $36 \mathrm{hpf}$ could not be detected (data not shown). But since robol and robo3 are expressed maternally (Challa et al., 2005), it is possible that they are present on longitudinal DA axon growth cones. Although we cannot exclude a contribution of maternally expressed Robos to early DA axonogenesis, we consider it unlikely that Robo activity would persist to guide axons after 3 or $4 \mathrm{~d}$ of development. To further exclude potential activities of Robo 1 and 3, we performed genetic and knockdown analysis in vivo. To that aim, we analyzed longitudinal THir tract formation in $a s t^{t i 272 z}$; $t w t^{t w 204}$ compound mutants, which were injected with a translation blocking robo1 MO. Elimination of Robo 1 and 3 did not affect lateral positioning of longitudinal tracts and did not enhance the ast mutant phenotype (see supplemental text and Fig. S4, available at www.jneurosci.org as supplemental material). Thus, DA tract positioning is primarily specified by Robo 2 function.

Analyzing z-projections of confocal image stacks of FISH for $n t n 1 a$ (Fig. $3 K$ ) or $n t n 1 b$ (Fig. $3 L$ ) demonstrated expression of both genes in broad domains extending from the forebrain through the hindbrain into the spinal cord at $24 \mathrm{hpf}$. The first DA axons projecting into the hindbrain bracket these $n t n 1 a$ and $n t n 1 b$ expression domains as revealed by $\mathrm{TH}$ labeling. Between 36 and $72 \mathrm{hpf}$, expression of $n t n 1 a$ and $n t n 1 b$ was maintained at the ventral midline in the hindbrain (data not shown). Note that netrin 2 and netrin4, the two other known secreted netrins in zebrafish, are not expressed in the ventral hindbrain at the stages analyzed (Park et al., 2005). Expression of the four zebrafish slit genes was detected at the midline of the hindbrain at $24 \mathrm{hpf}$ (Fig. $3 M-P)$. TH immunohistochemistry revealed that longitudinal 


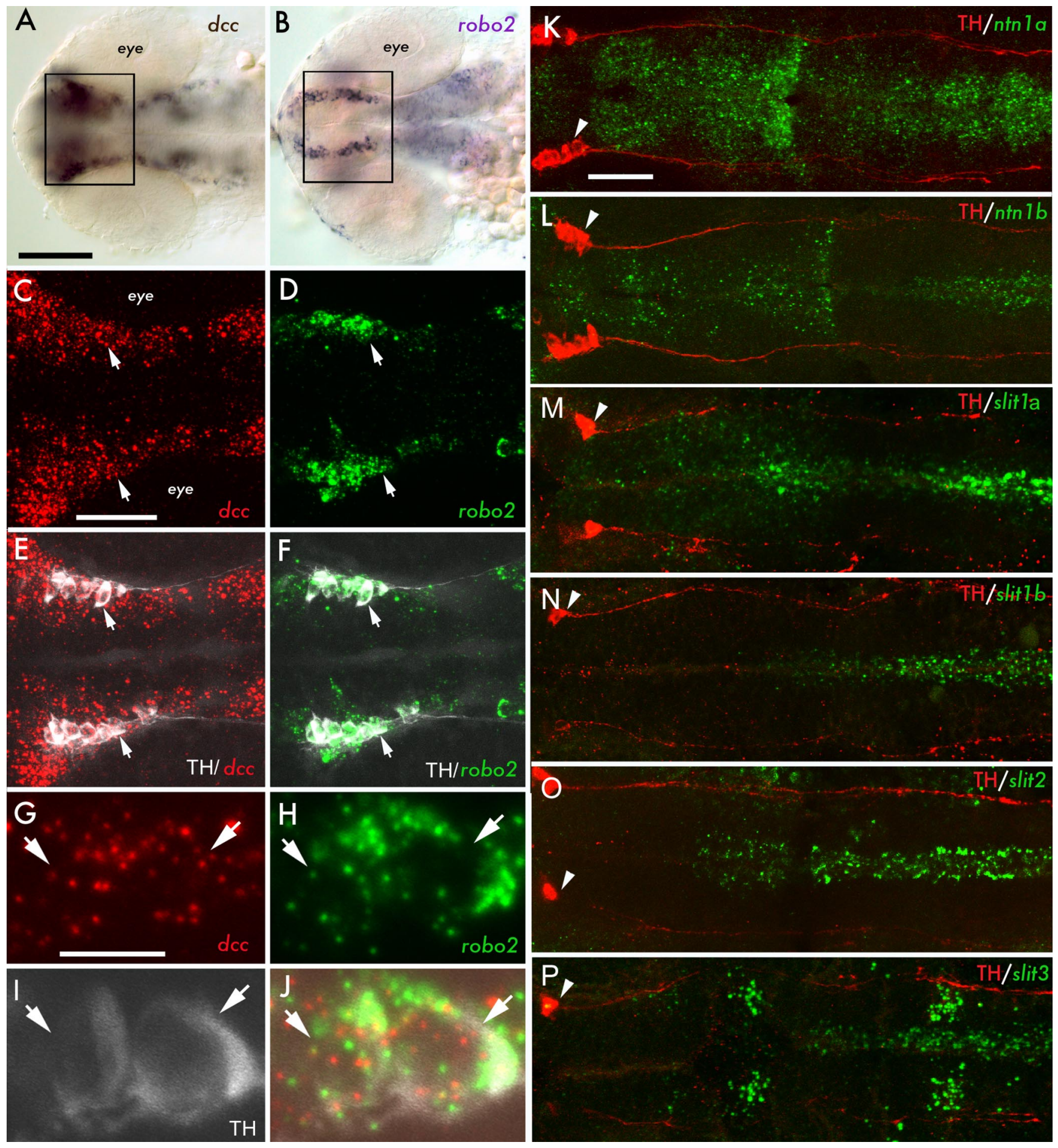

Figure 3. Spatial expression patterns of robo/slit and dcc/netrin genes are consistent with a role as guidance cues for longitudinal DA tracts. $\boldsymbol{A}-\boldsymbol{P}$, Dorsal views of single optical sections $(\boldsymbol{A}, \boldsymbol{B}, \mathbf{G}-\boldsymbol{J})$ or z-projections of confocal image stacks ( $\boldsymbol{C}-\boldsymbol{F}$ and $\boldsymbol{K}-\boldsymbol{P}$ ) of $24 \mathrm{hpfembryos}$ are shown. $\boldsymbol{A}, \boldsymbol{B}$, WHISH showing the expression of $d c c$ and robo 2 in ventral regions of the head at $24 \mathrm{hpf}$. The spatial relationship between $d c c$-expressing or robo2-expressing cells and TH-positive cells was analyzed by double fluorescent WHISH to dcc (red) and robo2 (green) in combination with TH immunohistochemistry (white). $C-F$, 0 verviews of the expression of $d c c(\boldsymbol{C}$; arrows) and robo2 ( $\boldsymbol{D}$; arrows) in relation to TH-positive neurons (arrows in $\boldsymbol{E}$ and $\boldsymbol{F}$ ) are shown for an area corresponding to the head region framed in $\boldsymbol{A}$ and $\boldsymbol{B}$. $\mathbf{G}-\mathbf{J}$, Higher

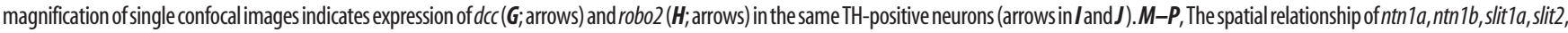
and slit3 expression in relation to DA axonal outgrowth was analyzed by fluorescent WHISH (green) and TH immunohistochemistry (red). $\boldsymbol{K}, \boldsymbol{L}, n t n 1 a(\boldsymbol{K})$ and $n t n 1 b(\boldsymbol{L})$ are expressed in broad domains that are encompassed by TH-positive axons. $\boldsymbol{M - 0}$, Expression of slit1a $(\boldsymbol{M})$, slittb $(\boldsymbol{N})$, slit2 $(\boldsymbol{O})$, and slit3 $(\boldsymbol{P})$ is found at the midline to which TH-positive axons grow at a certain distance. slit3 expression is additionally found in two bilateral clusters. The arrowheads in $\boldsymbol{K}-\boldsymbol{P}$ indicate DA neurons. Scale bars: (in $\boldsymbol{A}$ ) $\boldsymbol{A}, \boldsymbol{B}, 100 \mu \mathrm{m}$; (in $\boldsymbol{C} \mathbf{C}-\boldsymbol{F}, 50 \mu \mathrm{m}$; (in $\boldsymbol{G}$ ) $\mathbf{G}-\boldsymbol{J}, 10 \mu \mathrm{m}$; (in $\boldsymbol{K}$ ) $\boldsymbol{K}-\boldsymbol{P}, 50 \mu \mathrm{M}$.

DA axons grow laterally to the slit expression domains. Between 36 and $72 \mathrm{hpf}$, the expression of the four slit genes was maintained at the midline in the hindbrain (data not shown).

In summary, expression analysis revealed that robo2 is appar- ently the only Robo family member in zebrafish that is expressed by DA neurons in the ventral diencephalon during early stages of axonogenesis. Therefore, Robo 2 may mediate the repellent activities of the Slit ligands expressed by the midline to specify lateral 


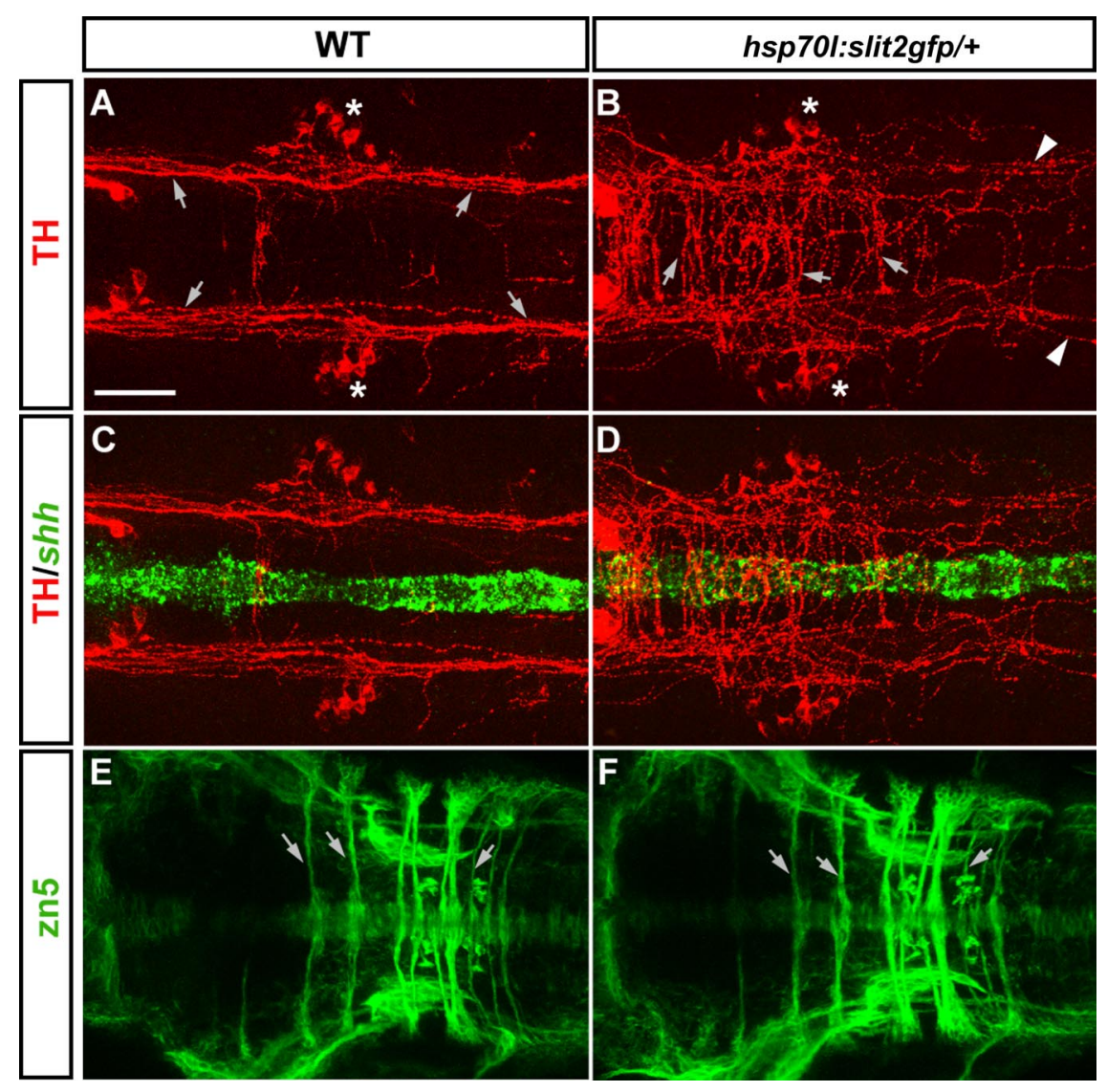

Figure 4. Ubiquitous misexpression of Slit2 causes pathfinding errors of longitudinal THir axons. $\boldsymbol{A}-\boldsymbol{E}$, Dorsal views of z-projections of confocal image stacks of the hindbrain of $38 \mathrm{hpf}(\boldsymbol{A}-\boldsymbol{D})$ or $48 \mathrm{hpf}(\boldsymbol{E}, \boldsymbol{D})$ embryos are shown, anterior on left. $\boldsymbol{A}, \mathrm{DA}$ Iongitudinal tract formation ( $\boldsymbol{A}$; arrows) in heat-shock-treated WT embryos is normal. $\boldsymbol{B}$, In Slit2gfp-overexpressing embryos, THir fibers deviate from their normal tracts and ectopically cross the midline (arrows). Longitudinal THir tracts are not present; only single axons growing at their normal positions are detectable (arrowheads). C, D, Fluorescent WHISH for shh in the same embryos shown in $\boldsymbol{A}$ and $\boldsymbol{B}$ indicates normal notochord and floor plate development in heatshock-treated WT $(\boldsymbol{C})$ and Slit2gfpoverexpressing embryos $(\boldsymbol{D}) . \boldsymbol{E}, \boldsymbol{F}$, zn5 labeling indicates normal formation of commissural tracts (arrows in $\boldsymbol{E}$ and $\boldsymbol{F}$ ) derived from hindbrain neurons in heat-shock-treated WT $(\boldsymbol{E})$ and $h$ sp70l:slit2gfp/+ embryos $(\boldsymbol{F})$. Asterisks in $\boldsymbol{A}$ and $\boldsymbol{B}$ indicate LC neurons. Scale bar: (in $\boldsymbol{A}) \boldsymbol{A}-\boldsymbol{F}, 50 \mu \mathrm{m}$.

positions of THir longitudinal tracts. In addition, we show that $d c c$ is coexpressed with robo2 by DA neurons in the ventral diencephalon during their initial phase of axonal outgrowth. Furthermore, two netrin genes, ntn1a and $n t n 1 b$, and four slit genes, slit1a, slit1b, slit2 and slit3, which are potential ligands for DCC and Robo2, respectively, are expressed in proximity to $\mathrm{TH}$ positive axons. Thus, the observed expression patterns are consistent with a role as guidance cues for longitudinal DA tracts.

\section{Ubiquitous misexpression of Slit2 impairs longitudinal pathfinding of DA axons}

To analyze whether localized Slit sources are critical for longitudinal DA tract formation, we used a transgenic line $\operatorname{Tg}(h s p 70 l$ : Slit2GFP) ${ }^{r w 015 d}$ (abbreviated as hsp70l:slit2gfp), which enables ubiquitous expression of a Slit2-GFP fusion protein following an increase in ambient temperature (to $39^{\circ} \mathrm{C}$ for $50 \mathrm{~min}$ ) (Yeo et al., 2001). Heterozygous hsp70l:slit2gfp embryos were heat-induced at $16 \mathrm{hpf}$ and reinduced at $26 \mathrm{hpf}$ to maintain Slit2-GFP expression level during the phase of initial DA axonal outgrowth. Heatinduced embryos were fixed at 38 and $48 \mathrm{hpf}$, DA axons were labeled by TH immunohistochemistry, and longitudinal tract formation was inspected by confocal microscopy. Because the results for both developmental stages were similar, embryos were com- bined for analysis. Heat-shock treatment does not affect longitudinal tract formation of THir axons in WT embryos $(n=$ 26) (Fig. $4 A$ ). In contrast, 27 of 32 of heatshock-treated hsp70l:slit2gfp/+ embryos displayed severe axonal pathfinding errors of THir axons (Fig. 4B). Instead of projecting at their normal longitudinal position parallel to the midline, many THir axons were detected to ectopically cross the midline. Consequently, the longitudinal THir fascicles do not form, but only single axons projecting at their normal lateral positions were detectable (Fig. $4 B)$. In situ hybridization for slit2 in heatshock-treated hsp70l:slit2gfp/+ embryos demonstrated that ubiquitous-induced slit2 expression levels exceeded the endogenous slit2 levels at the midline in WT embryos (supplemental Fig. S5A-D, available at www.jneurosci.org as supplemental material). This finding indicated that endogenous Slit gradients may be leveled out by ubiquitous overexpression in hsp70l:slit2gfp transgenic zebrafish. Ventral midline structures as revealed by $s h$ h in situ hybridization (Fig. 4C, $D ; n=10$ for both experimental groups) and transverse axon tract formation as revealed by zn-5 labeling (Fig. $4 E, F ; n=8$ for both experimental groups) in the hindbrain were not affected by ectopically overexpressing Slit2-GFP. To test whether heatshock treatment induces sufficient amounts of Slit2-GFP to affect axonal pathfinding, we analyzed pathfinding of Mauthner axons, which have been described to be misguided following ubiquitous Slit2-GFP overexpression (Yeo et al., 2004). In our heat-shocked experimental embryos, we observed similar Mauthner axons pathfinding defects as described previously (data not shown) (supplemental Fig. $\mathrm{S} 5 E, F$, available at www.jneurosci.org as supplemental material). Together, these results suggest that longitudinal THir axons in the hindbrain respond to Slit 2 and that a precise spatiotemporal distribution of Slit proteins is required for proper lateral positioning of these axons. Because of the ubiquitous overexpression of Slit2, THir axons may be unable to interpret the repulsive endogenous Slit signals derived from the midline.

Surprisingly, we found more pronounced midline crossing of DA axons in hsp70l:slit2gfp embryos compared with ast mutant embryos. This may be caused by a complete loss of Slit gradient orientation in hsp70l:slit2gfp. In contrast, in ast mutants, potential residual maternally derived Robol or 3 protein (Challa et al., 2005) may still being able to read the midline Slit repulsion. Also, receptor internalization may cause complete loss of Robo signaling in hsp70l:slit2gfp embryos. The observed difference in phenotype supports the notion of a graded requirement for Slit.

To further analyze the role of Slit signaling during longitudinal tract formation of THir axons, we tried to knock down slit gene function using various combinations of slit1a, slit1b, slit2, and slit3 antisense MOs. Unfortunately, these treatments led to severe morphological alterations at low amounts of injected 
MOs, which impeded the inspection of longitudinal tract formation of DA axons. Single injections of the different slit MOs ( 2 ng/embryo) allowed normal development and did not lead to abnormal pathfinding of THir longitudinal tracts when compared with control MO-injected embryos (data not shown). These observations may be explained by a compensatory effect of the three other remaining Slits. A similar redundant compensation has been observed for the three mammalian Slit homologs, since only slit1, slit2, and slit3 triple mutants display axon guidance defects of spinal cord commissural axons (Long et al., 2004).

\section{Knockdown of $d c c$ and netrin 1 gene} function restores lateral positioning of longitudinal DA tracts in ast

To test for a potential requirement of $d c c$ gene function during lateral positioning of DA axons, we injected $d c c$ antisense MOs at one-cell to two-cell stage into either WT or ast embryos. We used two dcctranslation-blocking MOs, which have been previously described to efficiently knock down $d c c$ gene function (DCCMO1 and DCC-MO2) (Suli et al., 2006). Injected embryos were fixed at $48 \mathrm{hpf}$, and DA axons were labeled by $\mathrm{TH}$ immunohistochemistry and analyzed by confocal microscopy.

Injection of $4.5 \mathrm{ng}$ of control $\mathrm{MO}$ into WT (Fig. 5A) or ast (Fig. 5B) embryos does not alter pathfinding of WT or ast DA longitudinal axons. In contrast, analysis of DA axonal projections in ast embryos injected with $4.5 \mathrm{ng}$ of $d c c-\mathrm{MO} 1$ (Fig. $5 C, D$ ) or $4.5 \mathrm{ng}$ of $d c c-\mathrm{MO} 2$ (Fig. $5 E$ ) revealed a "rescue" of the ast phenotype. Instead of growing toward the midline, many $\mathrm{TH}$-positive axons were shown to project in a WT-like manner at their lateral positions at the level of the LC neurons. The axons of the "rescued" DA longitudinal tracts appeared less fasciculated but otherwise grow within their normal trajectories. The observed restoration of longitudinal THir tracts in the hindbrain was not complete since we often detected single THir axons ectopically crossing the midline (Fig. 5C-E). To measure the observed effects, we performed a semiquantitative analysis. With regard to the longitudinal THir tracts, analyzed embryos were classified to have either a WT-like (Fig. 5A) or an ast phenotype (Fig. 5B). Embryos displaying an intermediate phenotype between WT-like and ast were classified into the ast group. Injection of $4.5 \mathrm{ng}$ of control MO does not affect longitudinal tract formation in WT embryos (Table 1, Fig. 5A), and all analyzed ast embryos injected with $4.5 \mathrm{ng}$ of control MO showed the ast phenotype with many axons growing toward and along the midline (Table 1, Fig. 5B, F). In contrast, following injection of $4.5 \mathrm{ng}$ of $d c c-\mathrm{MO} 1$ into ast embryos, only $41 \%$ of the inspected embryos displayed the ast phenotype (Table 1, Fig. $5 C, D, F$ ). The observed effect was dose-dependent, since injection of $2.25 \mathrm{ng}$ of $d c c-\mathrm{MO} 1$ resulted in a decreased fraction of rescued ast embryos (32\%; Table 1). Injection of a second $d c c$ morpholino of nonoverlap- ping sequence revealed similar results. Eighty-four percent of the ast embryos injected with $4.5 \mathrm{ng}$ of $d c c-\mathrm{MO} 2$ displayed a WT-like projection behavior (Table 1, Fig. 5E, F). In WT embryos injected with either $4.5 \mathrm{ng}$ of $d c c-\mathrm{MO} 1$ or $d c c-\mathrm{MO} 2$, pathfinding of longitudinal DA axons was indistinguishable from control MOinjected embryos (data not shown).

If DCC/Netrin1 signaling is indeed responsible for the observed "rescue" in ast mutants, then knocking down netrin1 gene function should reproduce the dcc knockdown phenotype. To test this hypothesis, we first knocked down both zebrafish netrin1 genes in ast embryos by coinjecting $4.5 \mathrm{ng}$ each of a splice blocking $n t n 1 a \mathrm{MO}$ and a translational blocking $n t n 1 b \mathrm{MO}$, which have been previously described to successfully inhibit netrin 1 function (Suli et al., 2006). Injection of 9 ng of control MO into WT or ast embryos does not change positioning of THir longitudinal axons in the hindbrain (Table 1; supplemental Fig. S6 $A, B, F$, available at www.jneurosci.org as supplemental material). In contrast, $74 \%$ of all ast embryos injected with $4.5 \mathrm{ng}$ each of $n t n 1 a$ and $n t n 1 b$ MO displayed a WT-like mediolateral positioning of THir longitudinal axons. (Table 1; supplemental Fig. S6C, D, F, available at www.jneurosci.org as supplemental material). Similar to the phenotypes observed after $d c c$ knockdown, injection of $n t n 1 a$ and $n t n 1 b$ MOs does not lead to a complete restoration of THir longitudinal tracts. Single THir axons ectopically crossing the midline were detected occasionally (supplemental Fig. S5D, 
Table 1. Effects of morpholino knockdown of Netrin signaling on THir longitudinal axon tract formation in WT and ast mutant hindbrains

\begin{tabular}{lllcc}
\hline & Genotype & Embryos $(n)$ & Astray (\%) & WT-like (\%) \\
\hline Control M0 4.5 ng & WT & 28 & $0 \pm 0$ & $100 \pm 0$ \\
Control M0 9 ng & WT & 52 & $0 \pm 0$ & $100 \pm 0$ \\
dcc M012.3 ng & ast & 46 & $68 \pm 4^{* * *}$ & $32 \pm 4^{* * *}$ \\
dcc M014.5 ng & ast & 68 & $41 \pm 16^{* * *}$ & $59 \pm 16^{* * *}$ \\
dcc M02 4.5 ng & ast & 28 & $16 \pm 9^{* * *}$ & $84 \pm 9^{* * *}$ \\
Control M0 4.5 ng & ast & 64 & $100 \pm 0$ & $0 \pm 0$ \\
ntn1a M0 4.5 ng & ast & 42 & $34 \pm 14^{* * *}$ & $66 \pm 14^{* * *}$ \\
ntn1b M0 4.5 ng & ast & 43 & $98 \pm 2$ & $2 \pm 2$ \\
ntn1a/ntn1b M0 4.5 ng each & ast & 55 & $26 \pm 5^{* * *}$ & $74 \pm 5^{* * *}$ \\
Control M09 ng & ast & 40 & $97 \pm 3$ & $3 \pm 3$
\end{tabular}

The following comparisons result in statistically significant differences in phenotypes ${ }^{* * *} p<0.001$ using Fisher's exact test): ast embryos injected with $2.3 \mathrm{ng}$ of $d c \mathrm{M} 01,4.5 \mathrm{ng}$ of $d c \mathrm{M} 01$, or $4.5 \mathrm{ng}$ of $d \mathrm{cc} \mathrm{M} 02$ were compared against ast embryos injected with $4.5 \mathrm{ng}$ of control $\mathrm{M} 0$; ast embryos injected with $4.5 \mathrm{ng}$ of $n t n 1 a \mathrm{M} 0,4.5 \mathrm{ng}$ of $n t n 1 b$ $\mathrm{M0}$, or with ntn 1a/ntn $16 \mathrm{M0} 4.5 \mathrm{ng}$ each were compared against ast embryos injected with $9 \mathrm{ng}$ of control M0.

available at www.jneurosci.org as supplemental material). To elucidate whether $n t n 1 a$ and $n t n 1 b$ are both required to the same degree to specify lateral positions of THir longitudinal tracts, we performed single injections of $n t n 1 a$ or $n t n 1 b$ MOs. Sixty-six percent of ast mutant embryos injected with $4.5 \mathrm{ng}$ of $n t n 1 a \mathrm{MO}$ displayed a WT-like mediolateral positioning of THir longitudinal tracts (Table 1; supplemental Fig. S6E, F, available at www. jneurosci.org as supplemental material). In contrast, $98 \%$ of ast embryos injected with $4.5 \mathrm{ng}$ of $n t n 1 b \mathrm{MO}$ still showed the ast phenotype (Table 1; supplemental Fig. S6F, available at www. jneurosci.org as supplemental material). Thus, DCC-mediated attraction toward the midline seems to rely mainly on $n t n 1 a$. Coinjection of either $4.5 \mathrm{ng}$ of $n t n 1 a$ and $n t n 1 b$ MOs in WT embryos did not affect pathfinding of longitudinal DA axons (data not shown), similar to the results observed after $d c c$ knockdown. Normal development of dopaminergic neurons and hindbrain structures after $d c c$ or $n t n 1$ knockdown were demonstrated by th in situ hybridization and labeling for MLF and reticulospinal axons (see supplemental text and Fig. S7, available at www.jneurosci.org as supplemental material).

Because reduction of either the receptor DCC or the ligand Netrin la leads to a WT-like positioning of longitudinal DA axons in the hindbrain of ast mutants, we conclude that attraction mediated by DCC/Netrin 1a is counteracted by repulsive Robo2/Slit signaling. Thus, lateral positions of longitudinal THir axons in the hindbrain may be specified by balancing Robo2/Slit repulsion and DCC/Netrin 1 attraction.

\section{Formation of DA longitudinal axon tracts requires HSPGs}

Previous genetic studies in Drosophila demonstrated that lateral positioning of longitudinal tracts by the midline repellent Slit requires Robo and HSPG or HS function (Johnson et al., 2004; Steigemann et al., 2004). Almost nothing is known about the requirement of HSPGs in longitudinal axon guidance in vertebrates. We therefore decided to analyze whether HSs or HSPGs are required for lateral positioning of longitudinal DA tracts. At first, we examined HS distribution in relation to DA axonal projection paths using anti-HS 10E4 antibody (David et al., 1992; Lee et al., 2004) in combination with anti-TH antibody labeling. Confocal analysis at $24 \mathrm{hpf}$ (data not shown) and $36 \mathrm{hpf}$ demonstrated that HSs are widely distributed throughout the brain and hindbrain and that longitudinal $\mathrm{TH}$-positive axons grow through anti-HS immunoreactive domains (Fig. 6A-C). Higher magnification demonstrated that $\mathrm{TH}$-positive axons appear to be surrounded by HSs (Fig. 6D-E). Localization of HSs within THir axons could not be observed. To further investigate the require- ment of HSPGs for pathfinding of DA longitudinal axons, we made use of box $x^{t m 70 g}$ mutants. The box ${ }^{t m 70 g}$ mutation affects the exostosin-like3 (extl3) gene shown to be required for HS synthesis (Lee et al., 2004). Confocal analysis of box $x^{t m 70 g}$ mutant embryos labeled with anti-TH antibody at $72 \mathrm{hpf}$ demonstrated pathfinding errors of THir longitudinal axons. Instead of retaining their lateral positions, individual DA axons could be observed which grow toward the midline in box $x^{t m 70 g}$ embryos. This was never observed in $b o x^{t m 70 g} /+$ siblings from the same clutch (Fig. 6G, $H$ ). The observed phenotypes in box ${ }^{t m 70 g}$ mutants were similar to the ast phenotype, albeit the degree of shifting toward the midline and ectopic midline crossing of DA axons in $b o x^{t m 70 g}$ appeared to be less severe. Overall development is grossly normal in box mutants at $24 \mathrm{hpf}$, likely because of maternally derived extl3 function (Lee et al., 2004). Using 3A10 antibody to label axonal trajectories of reticulospinal neurons in the hindbrain, we also found normal hindbrain development in box mutants at later stages (Fig. 6I, J). Our experiments demonstrate that THir axons are surrounded by HSs and that a reduction of HS levels in box $x^{t m 70 g}$ mutant embryos leads to axonal pathfinding errors similar to those observed in ast fish.

\section{Removal of both ast and box function enhances shifting of longitudinal THir axons toward the midline}

To explore the possibility that Robo/Slit and HSs/HSPGs may function in the same pathway, we analyzed the effect of attenuation or loss of box function on the ast phenotype and vice versa. $a s t^{t i 272 z} /+; b o x^{t m 70 g} /+$ parental fish were incrossed to generate double-mutant embryos as well as each mutant/heterozygous combination. Embryos were fixed at $96 \mathrm{hpf}$, colabeled with $\mathrm{TH}$ and 3A10 antibodies, and genotyped. Pathfinding of longitudinal THir axons was then inspected by confocal microscopy. Longitudinal tract formation was normal in genetically WT embryos derived from these incrosses (Fig. 7A). When comparing $a s t^{t i 272 z}$ / ast ${ }^{t i 272 z}$ with double-mutant ast ${ }^{\text {ti272z }} / a s t^{t i 272 z} ;$ box $^{\text {tm } 70 g} /$ box $x^{\text {tm } 70 g}$ embryos, we observed that in double mutants midline-shifted THir axons, after passing the area of the LC neurons, appeared to reach the midline at a more anterior level (Fig. 7E, I). Thus, loss of box function appears to enhance the THir axon shift toward the midline in ast. To quantify shifting of THir axons toward the midline, we counted all THir longitudinal axons projecting within the area delimited by the MLFs at the level of the anterior commissure of rhombomere three (Lorent et al., 2001) (see double-headed arrows in Fig. $7 B, F, J$ ). To exclude different absolute spacing between the MLFs in different genetic backgrounds, we measured their distance at the level of the anterior commissure of rhombomere three. This revealed no significant differences (average distance: WT $=35.7 \pm 1.9 \mu \mathrm{m} ;$ ast $^{t i 272 z}$ /

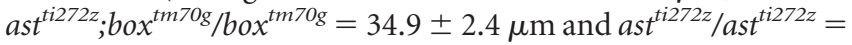
$35.6 \pm 2.5 \mu \mathrm{m})$. Furthermore, to control for general hindbrain development, we inspected crossing of Mauthner axons, which appeared unaffected in all analyzed embryos (data not shown). Analysis of THir projections revealed that in WT and $a s t^{t i 272 z} /+$; box $x^{t m 70 g} /+$ embryos projections of THir axons within this region were rarely detected (Fig. 7A-D, M). Removal of one Robo2 copy in $a s t^{t i 272 z} /+; b o x^{t m 70 g} / b o x^{t m 70 g}$ bo $x^{t m 70 g} / b o x^{t m 70 g}$ embryos did not yield an enhancement of the observed phenotype when compared with $b o x^{t m 70 g} / b o x^{t m 70 g}$ (Fig. 7M) embryos. In contrast, embryos that are $a s t^{t i 272 z} / a s t^{t i 272 z} ;$ box $x^{t m 70 g} /$ bo $x^{t m 70 g}$ displayed a significant increase in the number of longitudinal THir axons in the quantified area when compared with ast $t^{t i 272 z} / a s t^{t i 272 z}$ embryos (Fig. $7 E-M$ ). On the basis of formal genetic analysis alone, this would indicate that Robo/Slit and HSs/HSPGs act independently 
during longitudinal tract formation. However, the complexity of the experiment leaves several interpretations open. First, residual Robo/Slit signaling may still be active in ast $t^{t i 272 z} / a s t^{t i 272 z}$ embryos derived from incrosses of $a s t^{t i 272 z} /+$; box $^{\mathrm{tm} 70 \mathrm{~g}} /+$ parental fish. In such a scenario, a reduction of HS levels in $a s t^{t i 272 z}$ / ast ${ }^{t i 272 z}$;box $x^{t m 70 g} /$ box $x^{t m 70 g}$ embryos may further decrease repulsive Robo/Slit signaling and thereby indicate interaction by HSs/HSPGs and Robo/Slit. Second, HSs/HSPGs may act together with other guidance molecules. Third, HSs/HSPGs may also directly act as substrates for THir growth cones. Together, the analysis of the compound mutants points toward multiple functions of HSs/ HSPGs during longitudinal tract formation of DA neurons, which may comprise Robo/Slit-dependent and Robo/ Slit-independent functions.

\section{Discussion}

Proper formation of the dopamine neuromodulatory systems requires complex guidance of axons into distant CNS territories (for review, see Van den Heuvel and Pasterkamp, 2008). Although in vitro cell culture studies have indicated that neurite outgrowth of DA neurons is modulated by Slit and Netrin function (Lin et al., 2005; Lin and Isacson, 2006), mechanisms in the context of the embryo have not been analyzed so far, except for one study of THir contributions to the medial forebrain bundle (Bagri et al., 2002). Here, we investigated mechanisms of DA longitudinal tract formation in the zebrafish hindbrain. We demonstrate that repulsion by Robo2/Slit and attraction by DCC/Netrin 1 coordinately contribute to define lateral positions of hindbrain longitudinal DA tracts. Furthermore, we show that HSPG function is required to specify DA longitudinal tracts. On the basis of these findings, we propose a model in which long-range Slit and Netrin signals act in a concerted manner to constrain longitudinal DA axons to defined pathways (Fig. 8A). HSPGs distributed around THir longitudinal axons may contribute to proper long-range signaling via regulating stability, diffusion, or activity of ligands, for instance, Slits.

The following experimental findings support this model. Positioning of longitudinal DA axons is disrupted in Robo2deficient ast mutants, demonstrating a requirement for repulsive Robo2 function (Fig. $8 \mathrm{~B}$ ). The finding that the first longitudinal DA axons in ast embryos project normally may be explained by maternal contribution of Robo1/3 function (Challa et al., 2005). Mutant analysis also reveals that Robo2 activation prevents midline crossing of DA neurons. Our results are in accordance with previous work showing that Robo receptors specify lateral positions of longitudinal axon tracts in Drosophila (Bhat et al., 2007; Garbe and Bashaw, 2007) and vertebrates (Farmer et al., 2008).
Slits are ligands for Robo receptors (Brose et al., 1999) and mediate growth-cone repulsion (Dickson and Gilestro, 2006). Moreover, when Slit is expressed throughout the CNS of Drosophila, commissural axons display a phenotype similar to loss of function of Robo, indicating a deprivation in Slit responsiveness (Kidd et al., 1999). Similar to these findings, ubiquitous high-level overexpression of Slit2 in hsp70l:slit2gfp transgenic zebrafish embryos may level out the endogenous Slit midline gradient and thereby leads to an impairment of longitudinal DA growth cones to respond to Slit (Fig. 8C). These results are in agreement with previous studies demonstrating that localized sources and graded distribution of guidance cues are of crucial importance and that approximating an even distribution affects guidance similar to loss of expression (Harris et al., 1996; Kidd et al., 1999). Robo2 on the growth cones of DA axons would thus determine the lateral position of longitudinal DA axons by reading a medial $>$ lateral gradient of the secreted midline Slit repellents.

The finding that longitudinal DA growth cones are attracted 


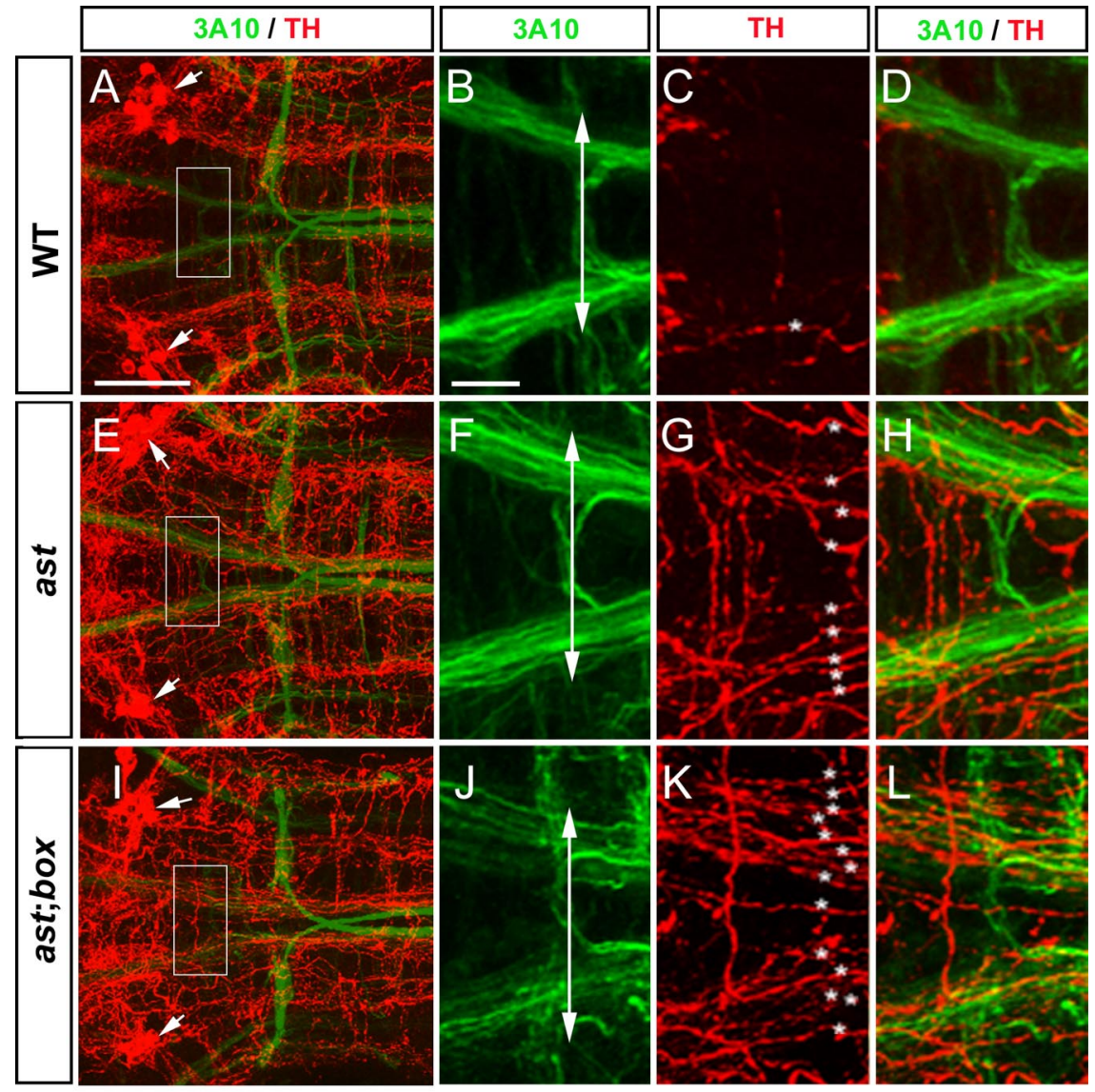

M

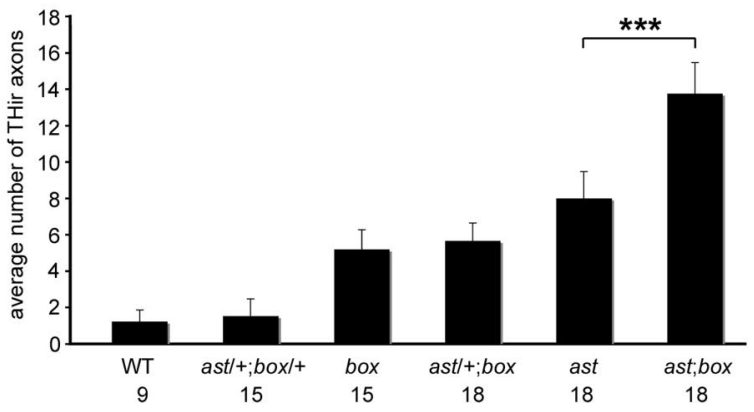

Figure 7. Simultaneous deletion of ast and box function enhances THir axon pathfinding defects. Dorsal views of confocal z-projections labeled with TH and $3 A 10$ antibody at 96 hpf are shown, anterior on left. In $A, E$, and $I$, an overview of the hindbrain is shown. Higher magnification in $\boldsymbol{B}-\boldsymbol{L}$ shows the region at the anterior commissure of rhombomere three (framed in $\boldsymbol{A}, \boldsymbol{E}$, and $\boldsymbol{I}$, respectively), which is used to quantify the phenotype (see text). In WT embryos, longitudinally projecting THir axons are rarely found in this territory defined by the MLFs ( $\boldsymbol{A}-\boldsymbol{D}$; double-headed arrow in $\boldsymbol{B}) . \boldsymbol{E}-\boldsymbol{H}$, In ast embryos, longitudinal THir projections are shifted toward the midline $(\boldsymbol{E})$, and some axons project within the region delimited by the MLFs $(\boldsymbol{F}-\boldsymbol{H}$; double-headed arrow in $\boldsymbol{F})$. $I-L$, In ast; box double-mutant embryos, shifting of THir longitudinal axons is enhanced, and the number of THir axons between the MLFs is increased (double-headed arrow in J). M, Quantification of THir axons within the area delimited by the MLFs as defined above. Error bars indicate SD of the mean. Significance was evaluated by unpaired Student's $t$ test. Asterisks indicate significant differences between ast and ast; box embryos ( $p<0.001)$. The number of embryos analyzed is indicated underneath each genotype. Arrows in $\boldsymbol{A}, \boldsymbol{E}$, and $\boldsymbol{I}$ point to $\mathrm{L} \boldsymbol{C}$ neurons, and asterisks in $\boldsymbol{C}, \boldsymbol{G}$, and $\boldsymbol{K}$ indicate THir axons growing in between the MLF axons. In $\boldsymbol{A}, \boldsymbol{E}$, and $\boldsymbol{I}$, the intensity of the $3 A 10$ labeling was reduced using Adobe Photoshop "Levels option" to allow better visualization of THir projections. Scale bars: (in $A) A, E, I, 50 \mu \mathrm{m}$; (in $B) B-D, F-H, J-L, 10 \mu \mathrm{m}$.

to the midline when Robo/Slit signaling is diminished reveals an attractive midline activity. Lateral positioning of longitudinal DA axons is partially restored in ast mutant embryos after reduction of either DCC or Netrin1 function and thus identifies DCC/Netrin signaling as such an attractive force. Knockdown of $d c c$ or netrin1 in WT embryos does not lead to abnormal DA longitudinal tract formation. This points to a more dominant role of Robo2/
Slit repulsion compared with DCC/Netrin attraction. However, it is also possible that residual levels of DCC or Netrin1 after MO knockdown are sufficient to properly guide longitudinal DA tracts in WT embryos.

How does repulsive Robo/Slit and attractive DCC/Netrin signaling cooperate to specify lateral positions of longitudinal DA tracts? One explanation for the observed phenotypes could be that Robo2 and DCC receptors on the DA growth cone integrate attractive and repulsive signals from the midline. When Robo2/Slit function is reduced or absent, Netrin signals become the dominating guidance cue, and DA axons are therefore attracted toward the midline (Fig. $8 B, C$ ). In contrast to Slits, a Netrin gradient emanating from the midline has been reported (Kennedy et al., 2006). There is another possible explanation for the observed phenotypes, which is based on studies suggesting that the major role of Robo/Slit signaling in commissural axon midline guidance is to inhibit responses to Netrin (Stein and Tessier-Lavigne, 2001; Bhat, 2005; Hiramoto and Hiromi, 2006). In such a scenario, DA growth cones deficient in Robo2/Slit signaling would be attracted toward the midline because Netrin attraction is no longer inhibited. These findings are in contrast to a recent study showing that Slit and Netrin influences on midline guidance are dictated by both independent and interdependent signaling functions of Robo and DCC receptors (Garbe and Bashaw, 2007). On the basis of our data, we cannot exclude one of these proposed mechanisms. Our finding of extensive midline crossing, rather than just lateral meandering, in hsp70l:slit2gfp embryos suggests that Netrin signaling may still be active even at high Slit activity. Thus, Robo and DCC signaling may provide independent inputs into growthcone behavior.

Surprisingly, our data indicate that alleviating or removing both attractive DCC/Netrin and repulsive Robo2/Slit signaling leads to a WT-like path of longitudinal DA axons. One possible interpretation is that in this experimental situation DCC and Robo signaling may balance each other similar to WT, albeit at lower overall signaling intensity. Alternatively, further guidance cues may compensate for the loss of DCC/Netrin attraction and Robo/Slit repulsion. Studies in rodents have shown that B-class Ephrins act locally to specify the dorsoventral position of longitudinally projecting post-crossing commissural axons (Imondi et al., 2000). Class 3 Semaphorins have been implicated to squeeze post-commissural axons out of the gray matter (Zou et al., 2000). Furthermore, Shh derived from the floor plate can attract commissural axons di- 

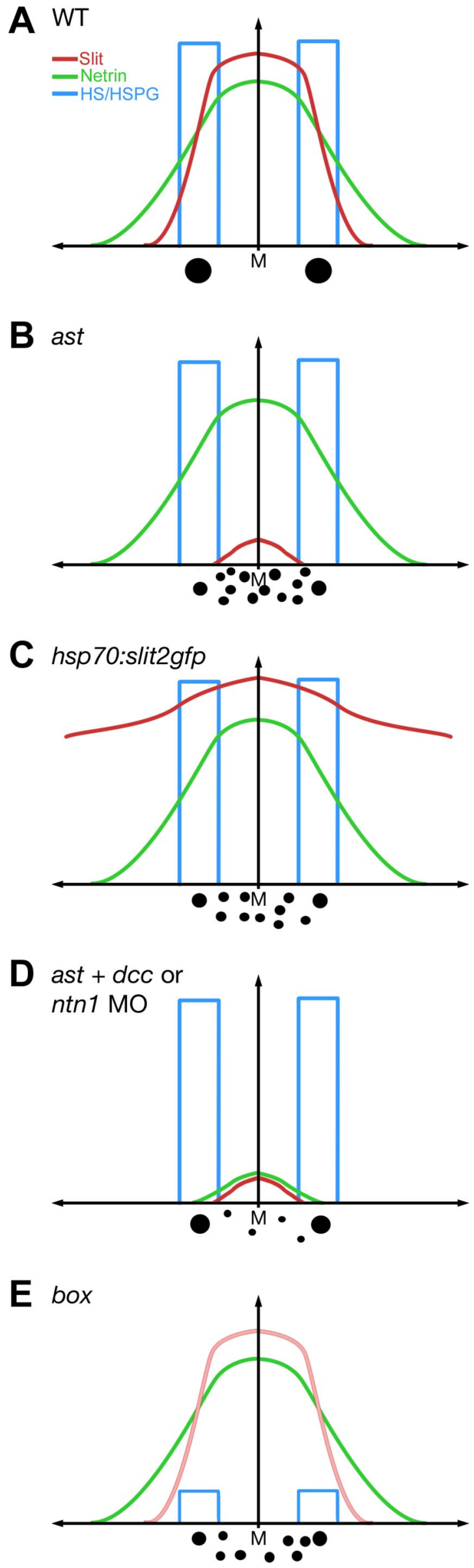

rectly (Charron et al., 2003; Okada et al., 2006). Although the function of these molecules has been studied in the context of commissural axon pathfinding, it is tempting to speculate that they may also control lateral positioning of longitudinal axons.

Investigating potential roles of HSPGs, we show that HSs are distributed around DA longitudinal axon tracts. Moreover, in box $x^{t m 70 g}$ mutants, longitudinal THir axons are medially shifted, a phenotype resembling ast mutants (Fig. $8 \mathrm{E}$ ). These observations suggest that HSPG and Robo/Slit signaling function together to control longitudinal DA tract formation. Indeed, previous studies in Drosophila have shown that HSPGs interact with Robo/Slit signaling in midline axon guidance most likely by controlling Slit stability or transport (Johnson et al., 2004; Steigemann et al., 2004); similarly, studies of zebrafish retinal axons showed that reducing HSPG levels using box; dak double mutants phenocopied the loss of Robo2 in ast mutants (Lee et al., 2004). Our analysis of the ast;box compound mutants may point toward a similar mechanism in THir axon pathfinding. Concordantly with the findings described in Drosophila, a reduction of HSs may alter Slit distribution or stability in the hindbrain. Therefore, it is conceivable that a reduction of HSs in $a s t^{t i 272 z}$; box ${ }^{t m 70 g}$ compound mutants further attenuates residual Slit signaling mediated by Robo1, Robo2, or Robo3 still present in ast embryos and enhances the phenotype. However, alternate interpretations are possible. The finding that ast;box compound mutants display a stronger phenotype than ast embryos suggests that HSPG may also function independently of Robo/Slit during longitudinal THir tract formation. HSPGs may modulate other guidance systems than Robo/Slit, such as Semaphorins (Kantor et al., 2004), or may serve as local guidance substrates (Kim et al., 2003; Akita et al., 2004). Consistent with our findings, HSPGs may also have multiple functions during longitudinal THir tract formation.

Are mechanisms of DA longitudinal pathfinding conserved? Mammalian A11 DA neurons, which are specified by Otp activity similar to DA neurons in the posterior tuberculum of zebrafish (Ryu et al., 2007), project to the spinal cord (Qu et al., 2006). Thus, mammalian A11 and zebrafish posterior tubercular DA neurons represent homologous diencephalospinal DA systems. Robo family members are expressed in the area of A11 group DA neurons (Marillat et al., 2002). Furthermore, studies in slit or robo mutants suggest that these genes function during lateral positioning of axon tracts within the lateral funiculus (Long et al., 2004) to

$\leftarrow$

Figure 8. The balance of repulsion by Slit and attraction by Netrin defines lateral positions of longitudinal DA axons in concert with HS/HSPG activity. Model of activities affecting positioning of THir longitudinal projections. Slit and Netrin gradients are indicated in red and green, respectively. The blue columns represent distribution of HSs. DA tracts or axons are indicated by black dots. $M$ indicates the midline. $\boldsymbol{A}$, Growth cones of longitudinal THir axons expressing $d c c$ and robo2 counterbalance attractive Netrin and repulsive Slit signals emanating from the midline to set up a specific position lateral to the midline. HSPGs in addition may improve the efficiency of Slit localization and/or signaling and thereby modulate the repellent Robo2/Slit signaling. $\boldsymbol{B}$, Repulsive Robo/Slit signaling is reduced in ast mutant embryos and longitudinal DA tracts grow closer to the midline as Netrin attraction abounds. C, Ubiquitous overexpression of Slit2 levels out the endogenous Slit gradient. Longitudinal DA growth cones are impaired to respond to Slit properly and, similar to the situation in ast mutants, are then attracted toward the midline by DCC/Netrin signaling. D, Injecting dec or ntn $1 \mathrm{MO}$ s into the ast mutant background surprisingly partially restores pathfinding of longitudinal DA axons. This may be caused by balanced attraction and repulsion at very low level or reflect substitution by other guidance cues. Small red or green $\operatorname{Slit}$ and Netrin gradients in $\boldsymbol{B}$ and $\boldsymbol{D}$ indicate residual repulsive or attractive activities. $\boldsymbol{E}$, In box embryos, HS levels are reduced, which may alter Slit distribution or activity, indicated here by light red Slit gradient. Because of decreased repulsive Robo2/Slit signaling longitudinal DA tracts grow closer to the midline. 
which A11 diencephalospinal projections also contribute (Skagerberg and Lindvall, 1985). Thus, Robo/Slit signaling may control pathfinding of A11 diencephalospinal projections. Interestingly, defects affecting A11 diencephalospinal circuitry, involved in spinal motor control, may contribute to RLS, a widespread syndrome that has been shown to be modulated by dopaminergic activity (Clemens et al., 2006).

In summary, DA axon growth cones appear to integrate signaling by repulsive and attractive guidance cues. HSPGs may modulate this signaling by controlling stability, transport, distribution, or activity of axon guidance ligands. HSPG distribution and loss-of-function studies in addition open the possibility that HSPGs may also serve as favorable local substrates. Signaling by Netrin and Slit have been considered as threshold phenomena, with Slit regulating growth-cone collapse (Nguyen Ba-Charvet et al., 1999). However, there has also been evidence for differential sensing of Slit concentrations (Harris et al., 1996; Kidd et al., 1999). Confirming this notion, we find loss-of-repulsive Slit activity at homogenous high Slit concentration levels. Thus, a concentration gradient is essential to realize Slit repulsive activity on DA growth cones. Netrin, however, appears to be present in the ventral hindbrain at levels above threshold to affect DA axon attraction to the midline. Knockdown of Netrin 1 indicates that this attractive activity is not prominently instructive for lateral positioning of DA axons, albeit combined inactivation of Slit and Netrin signaling reveals that Netrin is instructive in the absence of Slit. Our findings that Netrin causes midline guidance even at very high Slit levels argues against direct inhibition of DCC signaling by Robo activation but rather suggest integration of signals at downstream levels controlling growth-cone behavior. These observations support a model, in which Netrins predominantly provide directionality, whereas Slits specify position.

\section{References}

Akita K, Toda M, Hosoki Y, Inoue M, Fushiki S, Oohira A, Okayama M, Yamashina I, Nakada H (2004) Heparan sulphate proteoglycans interact with neurocan and promote neurite outgrowth from cerebellar granule cells. Biochem J 383:129-138.

Bagri A, Marin O, Plump AS, Mak J, Pleasure SJ, Rubenstein JL, TessierLavigne M (2002) Slit proteins prevent midline crossing and determine the dorsoventral position of major axonal pathways in the mammalian forebrain. Neuron 33:233-248.

Barresi MJ, Hutson LD, Chien CB, Karlstrom RO (2005) Hedgehog regulated Slit expression determines commissure and glial cell position in the zebrafish forebrain. Development 132:3643-3656.

Bedell VM, Yeo SY, Park KW, Chung J, Seth P, Shivalingappa V, Zhao J, Obara T, Sukhatme VP, Drummond IA, Li DY, Ramchandran R (2005) roundabout4 is essential for angiogenesis in vivo. Proc Natl Acad Sci U S A 102:6373-6378.

Bennett KL, Bradshaw J, Youngman T, Rodgers J, Greenfield B, Aruffo A, Linsley PS (1997) Deleted in colorectal carcinoma (DCC) binds heparin via its fifth fibronectin type III domain. J Biol Chem 272:26940-26946.

Bhat KM (2005) Slit-roundabout signaling neutralizes netrin-Frazzledmediated attractant cue to specify the lateral positioning of longitudinal axon pathways. Genetics 170:149-159.

Bhat KM, Gaziova I, Krishnan S (2007) Regulation of axon guidance by slit and netrin signaling in the Drosophila vental nerve cord. Genetics 176: 2235-2246.

Brose K, Bland KS, Wang KH, Arnott D, Henzel W, Goodman CS, TessierLavigne M, Kidd T (1999) Slit proteins bind Robo receptors and have an evolutionarily conserved role in repulsive axon guidance. Cell 96:795-806.

Burgess HA, Johnson SL, Granato M (2009) Unidirectional startle responses and disrupted left-right coordination of motor behaviors in robo3 mutant zebrafish. Genes Brain Behav. Advance online publication. Retrieved May 20, 2009. doi:10.111/j.1601-183X.2009.00499.x.

Campbell DS, Stringham SA, Timm A, Xiao T, Law MY, Baier H, Nonet ML, Chien CB (2007) Slitla inhibits retinal ganglion cell arborization and synaptogenesis via Robo2-dependent and -independent pathways. Neuron 55:231-245.

Chalasani SH, Sabol A, Xu H, Gyda MA, Rasband K, Granato M, Chien CB, Raper JA (2007) Stromal cell-derived factor-1 antagonizes slit/robo signaling in vivo. J Neurosci 27:973-980.

Challa AK, McWhorter ML, Wang C, Seeger MA, Beattie CE (2005) Robo3 isoforms have distinct roles during zebrafish development. Mech Dev 122:1073-1086.

Charron F, Tessier-Lavigne M (2005) Novel brain wiring functions for classical morphogens: a role as graded positional cues in axon guidance. Development 132:2251-2262.

Charron F, Stein E, Jeong J, McMahon AP, Tessier-Lavigne M (2003) The morphogen sonic hedgehog is an axonal chemoattractant that collaborates with netrin-1 in midline axon guidance. Cell 113:11-23.

Chedotal A (2007) Slits and their receptors. Adv Exp Med Biol 621:65-80.

Chedotal A, Pourquie O, Sotelo C (1995) Initial tract formation in the brain of the chick embryo: selective expression of the BEN/SC1/DM-GRASP cell adhesion molecule. Eur J Neurosci 7:198-212.

Chitnis AB, Kuwada JY (1990) Axonogenesis in the brain of zebrafish embryos. J Neurosci 10:1892-1905.

Clemens S, Rye D, Hochman S (2006) Restless legs syndrome: revisiting the dopamine hypothesis from the spinal cord perspective. Neurology 67 : $125-130$.

Colamarino SA, Tessier-Lavigne M (1995) The role of the floor plate in axon guidance. Annu Rev Neurosci 18:497-529.

David G, Bai XM, Van der Schueren B, Cassiman JJ, Van den Berghe H (1992) Developmental changes in heparan sulfate expression: in situ detection with mAbs. J Cell Biol 119:961-975.

Devine CA, Key B (2008) Robo-Slit interactions regulate longitudinal axon pathfinding in the embryonic vertebrate brain. Dev Biol 313:371-383.

Dickson BJ, Gilestro GF (2006) Regulation of commissural axon pathfinding by slit and its Robo receptors. Annu Rev Cell Dev Biol 22:651-675.

Dodd J, Morton SB, Karagogeos D, Yamamoto M, Jessell TM (1988) Spatial regulation of axonal glycoprotein expression on subsets of embryonic spinal neurons. Neuron 1:105-116.

Easter SS Jr, Ross LS, Frankfurter A (1993) Initial tract formation in the mouse brain. J Neurosci 13:285-299.

Easter SS Jr, Burrill J, Marcus RC, Ross LS, Taylor JS, Wilson SW (1994) Initial tract formation in the vertebrate brain. Prog Brain Res 102:79-93.

Farmer WT, Altick AL, Nural HF, Dugan JP, Kidd T, Charron F, Mastick GS (2008) Pioneer longitudinal axons navigate using floor plate and Slit/ Robo signals. Development 135:3643-3653.

Filippi A, Duerr K, Ryu S, Willaredt M, Holzschuh J, Driever W (2007) Expression and function of nr4a2, $1 \mathrm{mx} 1 \mathrm{~b}$, and pitx 3 in zebrafish dopaminergic and noradrenergic neuronal development. BMC Dev Biol 7:135.

Fricke C, Chien CB (2005) Cloning of full-length zebrafish dcc and expression analysis during embryonic and early larval development. Dev Dyn 234:732-739.

Fricke C, Lee JS, Geiger-Rudolph S, Bonhoeffer F, Chien CB (2001) astray, a zebrafish roundabout homolog required for retinal axon guidance. Science 292:507-510.

Garbe DS, Bashaw GJ (2007) Independent functions of Slit-Robo repulsion and Netrin-Frazzled attraction regulate axon crossing at the midline in Drosophila. J Neurosci 27:3584-3592.

Granato M, van Eeden FJ, Schach U, Trowe T, Brand M, Furutani-Seiki M, Haffter P, Hammerschmidt M, Heisenberg CP, Jiang YJ, Kane DA, Kelsh RN, Mullins MC, Odenthal J, Nusslein-Volhard C (1996) Genes controlling and mediating locomotion behavior of the zebrafish embryo and larva. Development 123:399-413.

Harris R, Sabatelli LM, Seeger MA (1996) Guidance cues at the Drosophila CNS midline: identification and characterization of two Drosophila Netrin/UNC-6 homologs. Neuron 17:217-228.

Hauptmann G, Gerster T (1994) Two-color whole-mount in situ hybridization to vertebrate and Drosophila embryos. Trends Genet 10:266.

Hiramoto M, Hiromi Y (2006) ROBO directs axon crossing of segmental boundaries by suppressing responsiveness to relocalized Netrin. Nat Neurosci 9:58-66.

Hoffman TL, Javier AL, Campeau SA, Knight RD, Schilling TF (2007) Tfap2 transcription factors in zebrafish neural crest development and ectodermal evolution. J Exp Zoolog B Mol Dev Evol 308:679-691.

Holzschuh J, Ryu S, Aberger F, Driever W (2001) Dopamine transporter ex- 
pression distinguishes dopaminergic neurons from other catecholaminergic neurons in the developing zebrafish embryo. Mech Dev 101:237-243.

Holzschuh J, Barrallo-Gimeno A, Ettl AK, Durr K, Knapik EW, Driever W (2003) Noradrenergic neurons in the zebrafish hindbrain are induced by retinoic acid and require tfap2a for expression of the neurotransmitter phenotype. Development 130:5741-5754.

Hutson LD, Jurynec MJ, Yeo SY, Okamoto H, Chien CB (2003) Two divergent slit1 genes in zebrafish. Dev Dyn 228:358-369.

Imondi R, Wideman C, Kaprielian Z (2000) Complementary expression of transmembrane ephrins and their receptors in the mouse spinal cord: a possible role in constraining the orientation of longitudinally projecting axons. Development 127:1397-1410.

Inatani M, Irie F, Plump AS, Tessier-Lavigne M, Yamaguchi Y (2003) Mammalian brain morphogenesis and midline axon guidance require heparan sulfate. Science 302:1044-1046.

Johnson KG, Ghose A, Epstein E, Lincecum J, O’Connor MB, Van Vactor D (2004) Axonal heparan sulfate proteoglycans regulate the distribution and efficiency of the repellent slit during midline axon guidance. Curr Biol 14:499-504.

Kantor DB, Chivatakarn O, Peer KL, Oster SF, Inatani M, Hansen MJ, Flanagan JG, Yamaguchi Y, Sretavan DW, Giger RJ, Kolodkin AL (2004) Semaphorin $5 \mathrm{~A}$ is a bifunctional axon guidance cue regulated by heparan and chondroitin sulfate proteoglycans. Neuron 44:961-975.

Kennedy TE, Serafini T, de la Torre JR, Tessier-Lavigne M (1994) Netrins are diffusible chemotropic factors for commissural axons in the embryonic spinal cord. Cell 78:425-435.

Kennedy TE, Wang H, Marshall W, Tessier-Lavigne M (2006) Axon guidance by diffusible chemoattractants: a gradient of netrin protein in the developing spinal cord. J Neurosci 26:8866-8874.

Kidd T, Bland KS, Goodman CS (1999) Slit is the midline repellent for the robo receptor in Drosophila. Cell 96:785-794.

Kim MJ, Cotman SL, Halfter W, Cole GJ (2003) The heparan sulfate proteoglycan agrin modulates neurite outgrowth mediated by FGF-2. J Neurobiol 55:261-277.

Krauss S, Concordet JP, Ingham PW (1993) A functionally conserved homolog of the Drosophila segment polarity gene hh is expressed in tissues with polarizing activity in zebrafish embryos. Cell 75:1431-1444.

Lauderdale JD, Davis NM, Kuwada JY (1997) Axon tracts correlate with netrin-1a expression in the zebrafish embryo. Mol Cell Neurosci 9:293-313.

Lee JS, Ray R, Chien CB (2001) Cloning and expression of three zebrafish roundabout homologs suggest roles in axon guidance and cell migration. Dev Dyn 221:216-230.

Lee JS, von der Hardt S, Rusch MA, Stringer SE, Stickney HL, Talbot WS, Geisler R, Nusslein-Volhard C, Selleck SB, Chien CB, Roehl H (2004) Axon sorting in the optic tract requires HSPG synthesis by ext2 (dackel) and extl3 (boxer). Neuron 44:947-960.

Liang Y, Annan RS, Carr SA, Popp S, Mevissen M, Margolis RK, Margolis RU (1999) Mammalian homologues of the Drosophila slit protein are ligands of the heparan sulfate proteoglycan glypican-1 in brain. J Biol Chem 274:17885-17892.

Lin L, Isacson O (2006) Axonal growth regulation of fetal and embryonic stem cell-derived dopaminergic neurons by Netrin-1 and Slits. Stem Cells 24:2504-2513.

Lin L, Rao Y, Isacson O (2005) Netrin-1 and slit-2 regulate and direct neurite growth of ventral midbrain dopaminergic neurons. Mol Cell Neurosci 28:547-555.

Long H, Sabatier C, Ma L, Plump A, Yuan W, Ornitz DM, Tamada A, Murakami F, Goodman CS, Tessier-Lavigne M (2004) Conserved roles for Slit and Robo proteins in midline commissural axon guidance. Neuron 42:213-223.

Lorent K, Liu KS, Fetcho JR, Granato M (2001) The zebrafish space cadet gene controls axonal pathfinding of neurons that modulate fast turning movements. Development 128:2131-2142.

Marillat V, Cases O, Nguyen-Ba-Charvet KT, Tessier-Lavigne M, Sotelo C, Chedotal A (2002) Spatiotemporal expression patterns of slit and robo genes in the rat brain. J Comp Neurol 442:130-155.

Mastick GS, Easter SS Jr (1996) Initial organization of neurons and tracts in the embryonic mouse fore- and midbrain. Dev Biol 173:79-94.

Matsumoto Y, Irie F, Inatani M, Tessier-Lavigne M, Yamaguchi Y (2007) Netrin-1/DCC signaling in commissural axon guidance requires cellautonomous expression of heparan sulfate. J Neurosci 27:4342-4350.

McLean DL, Fetcho JR (2004) Ontogeny and innervation patterns of dopa- minergic, noradrenergic, and serotonergic neurons in larval zebrafish. J Comp Neurol 480:38-56.

Moore SW, Tessier-Lavigne M, Kennedy TE (2007) Netrins and their receptors. Adv Exp Med Biol 621:17-31.

Nguyen Ba-Charvet KT, Brose K, Marillat V, Kidd T, Goodman CS, TessierLavigne M, Sotelo C, Chedotal A (1999) Slit2-mediated chemorepulsion and collapse of developing forebrain axons. Neuron 22:463-473.

Okada A, Charron F, Morin S, Shin DS, Wong K, Fabre PJ, Tessier-Lavigne M, McConnell SK (2006) Boc is a receptor for sonic hedgehog in the guidance of commissural axons. Nature 444:369-373.

Ondo WG, Zhao HR, Le WD (2007) Animal models of restless legs syndrome. Sleep Med 8:344-348.

Park KW, Urness LD, Senchuk MM, Colvin CJ, Wythe JD, Chien CB, Li DY (2005) Identification of new netrin family members in zebrafish: developmental expression of netrin 2 and netrin 4. Dev Dyn 234:726-731.

Qu S, Ondo WG, Zhang X, Xie WJ, Pan TH, Le WD (2006) Projections of diencephalic dopamine neurons into the spinal cord in mice. Exp Brain Res 168:152-156.

Rajagopalan S, Vivancos V, Nicolas E, Dickson BJ (2000) Selecting a longitudinal pathway: Robo receptors specify the lateral position of axons in the Drosophila CNS. Cell 103:1033-1045.

Ryu S, Mahler J, Acampora D, Holzschuh J, Erhardt S, Omodei D, Simeone A, Driever W (2007) Orthopedia homeodomain protein is essential for diencephalic dopaminergic neuron development. Curr Biol 17:873-880.

Sabatier C, Plump AS, Le M, Brose K, Tamada A, Murakami F, Lee EY, Tessier-Lavigne M (2004) The divergent Robo family protein rig-1/ Robo3 is a negative regulator of slit responsiveness required for midline crossing by commissural axons. Cell 117:157-169.

Serafini T, Kennedy TE, Galko MJ, Mirzayan C, Jessell TM, Tessier-Lavigne M (1994) The netrins define a family of axon outgrowth-promoting proteins homologous to C. elegans UNC-6. Cell 78:409-424.

Serafini T, Colamarino SA, Leonardo ED, Wang H, Beddington R, Skarnes WC, Tessier-Lavigne M (1996) Netrin-1 is required for commissural axon guidance in the developing vertebrate nervous system. Cell 87:1001-1014.

Simpson JH, Kidd T, Bland KS, Goodman CS (2000) Short-range and longrange guidance by slit and its Robo receptors: Robo and Robo2 play distinct roles in midline guidance. Neuron 28:753-766.

Skagerberg G, Lindvall O (1985) Organization of diencephalic dopamine neurones projecting to the spinal cord in the rat. Brain Res 342:340-351.

Steigemann P, Molitor A, Fellert S, Jackle H, Vorbruggen G (2004) Heparan sulfate proteoglycan syndecan promotes axonal and myotube guidance by slit/robo signaling. Curr Biol 14:225-230.

Stein E, Tessier-Lavigne M (2001) Hierarchical organization of guidance receptors: silencing of netrin attraction by slit through a Robo/DCC receptor complex. Science 291:1928-1938.

Strahle U, Fischer N, Blader P (1997) Expression and regulation of a netrin homologue in the zebrafish embryo. Mech Dev 62:147-160.

Suli A, Mortimer N, Shepherd I, Chien CB (2006) Netrin/DCC signaling controls contralateral dendrites of octavolateralis efferent neurons. J Neurosci 26:13328-13337.

Trevarrow B, Marks DL, Kimmel CB (1990) Organization of hindbrain segments in the zebrafish embryo. Neuron 4:669-679.

Van den Heuvel DM, Pasterkamp RJ (2008) Getting connected in the dopamine system. Prog Neurobiol 85:75-93.

Westerfield M (1995) The zebrafish book. A guide for the laboratory use of zebrafish (Danio rerio), Ed 3. Eugene, OR: University of Oregon.

Wilson SW, Ross LS, Parrett T, Easter SS Jr (1990) The development of a simple scaffold of axon tracts in the brain of the embryonic zebrafish, Brachydanio rerio. Development 108:121-145.

Yeo SY, Little MH, Yamada T, Miyashita T, Halloran MC, Kuwada JY, Huh TL, Okamoto H (2001) Overexpression of a slit homologue impairs convergent extension of the mesoderm and causes cyclopia in embryonic zebrafish. Dev Biol 230:1-17.

Yeo SY, Miyashita T, Fricke C, Little MH, Yamada T, Kuwada JY, Huh TL, Chien CB, Okamoto H (2004) Involvement of Islet-2 in the Slit signaling for axonal branching and defasciculation of the sensory neurons in embryonic zebrafish. Mech Dev 121:315-324.

Zolessi FR, Poggi L, Wilkinson CJ, Chien CB, Harris WA (2006) Polarization and orientation of retinal ganglion cells in vivo. Neural Dev 1:2.

Zou Y, Stoeckli E, Chen H, Tessier-Lavigne M (2000) Squeezing axons out of the gray matter: a role for slit and semaphorin proteins from midline and ventral spinal cord. Cell 102:363-375. 